\title{
Artificial Intelligence in Business-to-Business Marketing: A Bibliometric Analysis of Current Research Status, Development and Future Directions
}

Runyue Han ${ }^{\mathrm{a}}$, Hugo K.S. Lam ${ }^{\mathrm{a}}$, Yuanzhu Zhan ${ }^{\mathrm{a} *}$, Yichuan Wang ${ }^{\mathrm{b}}$, Yogesh K. Dwivedi ${ }^{\mathrm{c}}$, Kim Hua $\operatorname{Tan}^{\mathrm{d}}$,

${ }^{a}$ Management School, University of Liverpool, United Kingdom; ${ }^{b}$ Management School, University of Sheffield, United Kingdom; ${ }^{c}$ School of Management, Swansea University, United Kingdom; ${ }^{d}$ University of Nottingham Business School, United Kingdom

\begin{abstract}
Purpose - Although the value of AI has been acknowledged by companies, the literature shows challenges concerning AI-enabled B2B marketing innovation, as well as the diversity of roles AI can play in this regard. Accordingly, this study investigates the approaches that AI can be used for enabling B2B marketing innovation.

Design/methodology/approach - Applying a bibliometric research method, this study systematically investigates the literature regarding AI-enabled B2B marketing. It synthesises state-of-the-art knowledge from 221 journal articles published between 1990 and 2021.
\end{abstract}

Findings - Apart from offering specific information regarding the most influential authors and most frequently cited articles, the study further categorises the use of AI for innovation in B2B marketing into five domains, identified the main trends in the literature, and suggest directions for future research.

Practical implications - Through our identified five domains, practitioners can assess their current use of AI ability in terms of their conceptualisation capability, technological applications, and identify their future needs in the relevant domains in order to make appropriate decisions on whether to invest in AI. Thus, the research outcomes can help companies to realise their digital marketing innovation strategy through AI.

Originality/value - While more and more studies acknowledge the potential value of AI in B2B marketing, few attempts have been made to synthesise the literature. The results from the study can contribute by 1) obtaining and comparing the most influential works based on a series of analyses; 2) identifying five domains of research into how AI can be used for facilitating B2B marketing innovation; and 3) classifying relevant articles into five different time periods in order to identify both past trends and future directions in this specific field.

Keywords: Artificial intelligence, business-to-business marketing, innovation, systematic literature review, bibliometric analysis, content analysis. 


\section{Introduction}

In recent years, technological innovations in business-to-business (B2B) marketing have become a field of increasing research interest (Paschen et al., 2019; Kumar et al., 2020; Park and Park, 2003; Wang et al., 2017; Leung et al., 2019). Particularly, the advent of information and communication technologies has transformed value-creation activities at every stage of B2B marketing (Park and Park, 2003; Paschen et al., 2020a). With previous technological revolutions, notably the widespread use of social media (Chan et al., 2017; Dwivedi et al., 2019a; Wang et al., 2020b), the advent of additive manufacturing (van Loon and Van Wassenhove, 2018) and the Internet of Things (Leung et al., 2019; Fu et al., 2017), decision-making remained with humans (Chan et al., 2007), albeit supported by enhanced information processing capabilities for data capture, analysis and transformation. However, artificial intelligence (AI) is set to change in remarkable ways of the interactions between machines and humans (Paschen et al., 2019), allowing computers to make effective decisions with little or no human involvement (Duan et al., 2019; Dwivedi et al., 2019b; Park and Park, 2003).

According to Martínez-López and Casillas (2013), AI refers to computer systems that develop feasible automated solutions to tasks which typically require human intelligence. AI is becoming a major disruptive force in commercial terms. It can radically improve an existing company's operations and create a space for entirely new businesses (Dadouchi and Agard, 2018; Davenport et al., 2020; Dwivedi et al., 2020; Grover et al., 2020; Pillai et al., 2020; Wilson and Bettis-Outland, 2019). Notably, there is increasing interest in the application of AI technologies to B2B marketing innovation (Kot and Leszczyński, 2020; Dong et al., 2014; Tan et al., 2012; Hosseini et al., 2010; Gessner and Scott, 2009). For instance, a survey conducted by Google and MIT Technology Review collected data from over 1,400 executives and found that industrial marketing services ranked among the top areas regarding the implementation of AI for innovation (Simonite, 2018). Specifically, AI can be used by B2B marketing firms to extract information from vast amounts of data, which hitherto would have been difficult and expensive, if not impossible, for B2B marketers (Hosseini et al., 2010; Dong et al., 2014). The information collected can be used to improve their data management, customisation, operations and marketing strategies.

Nonetheless, the literature shows an inconsistency between B2B companies' 
enthusiasm for AI's business opportunities and practical guidelines regarding how companies should embrace it (Daskou and Mangina, 2003; Paschen et al., 2019; Martínez-López and Casillas, 2013). While more and more studies acknowledge the potential value of $\mathrm{AI}$ in $\mathrm{B} 2 \mathrm{~B}$ marketing, few attempts have been made to synthesise the literature. This is problematic as the results generated from different studies tend to be limited, and there is a lack of comprehensive management guidelines to enable companies to integrate $\mathrm{AI}$ as an enabler for innovation into their B2B marketing. For instance, Paschen et al. (2019) and Pandey et al. (2020) propose conceptual frameworks for AI-supported marketing innovation, but their research focuses mainly on market knowledge management. In a B2B marketing context, the emphasis of most studies is on digital mediation via specific technologies such as social media, the Internet of Things and augmented reality (Dwivedi et al., 2019a; Kumar et al., 2020; Brosan, 2012). Therefore, no previous study has comprehensively investigated the literature on how AI can be used for innovation and gaining a competitive edge in B2B marketing.

Additionally, recent studies have revealed the significance to further explore the use of AI in B2B marketing innovation, asking for more research to be conducted in this field (Chan et al., 2011; Paschen et al., 2020b; Giri et al., 2019). Typically, discussion of the use of AI as an enabler for innovation in B2B marketing has generated a great diversity of suggestions (Giri et al., 2019) because a wide variety of AI technologies can be applied to a broad range of B2B marketing activities. Accordingly, a summary of the uses of different AI technologies for innovation in B2B marketing is needed. Furthermore, no study has analysed trends in research on the application of AI for B2B marketing innovation or provided suggestions for directions in future research. Chan et al. (2011) call for further work to explore the challenges in the application of AI for B2B marketing innovation, especially in relation to the workforce to support businesses in developing their innovative practices (Daskou and Mangina, 2003; Paschen et al., 2020a; Fish et al., 1995). In light of the above, the present study sought to address two research questions:

$R Q$ 1: How AI can be implemented to enable B2B marketing innovations?

$R Q$ 2: What are the main trends in the research on the use of AI as an enabler for innovation in B2B marketing, and what directions is future research likely to take?

To address these questions, the study adopts a bibliometric research method. Apart from offering specific information regarding the most influential authors and most frequently cited articles, the thematic analysis summarises the AI-enabled B2B 
marketing literature within five domains for innovation: 1) AI-enabled customer relationship management, 2) B2B sales forecasting through AI, 3) the use of AI for value co-creation, 4) AI-enabled operations management, and 5) conceptual frameworks for AI in B2B marketing. In addition, this study identifies the main research trends that have been in the application of AI as an enabler for innovation within B2B marketing, as well as likely future research directions by conducting a content analysis of the literature published over the past three decades. The results offer insights to researchers as well as managerial guidance for practitioners.

The rest of this paper is structured as follows. Section 2 reviews the literature on AI, specifically its application for B2B marketing innovation, and that on bibliometrics as a research method. Section 3 introduces the research methods applied in this study, and Section 4 conducts a series of analyses (key authors and journals, citation and cocitation analysis) to identify the prominent domains of the research. Section 5 presents the findings of a cluster analysis of the five 'domains' identified for the use of AI as an enabler for innovation in B2B marketing. Section 6 determines the main trends in the literature and directions for future research through content analysis. Finally, Section 7 concludes by highlighting the implications of the findings as well as the study's limitations.

\section{An introductory overview of AI and its application for B2B marketing innovation, and of bibliometric analysis}

The literature on AI has expanded to such an extent that summarising the proliferation of research is a complex issue (Wamba et al., 2020; Duan et al., 2019; Wu et al., 2014; Belanche et al., 2019). The term 'AI' itself can cause confusion. In popular usage, it often indicates a computer's capacity for human-like creativity (Simonite, 2018; Paschen et al., 2019), but in a business context, AI normally refers to machine learning and expert systems that process vast amounts of data using embedded algorithms (Yang et al., 2010; Schellhorn, 2009; Piao et al., 2009). Thus, it is helpful to consider general AI and narrow AI. General AI refers to the intelligence displayed by a computer capable of addressing any intellectual problem that a human being can (Paschen et al., 2019), while narrow AI indicates a particular kind of intelligence in which a computer performs better than humans on some narrowly specified tasks (Wilson and Bettis-Outland, 2019). This study looks solely at narrow AI. Therefore, 
the definition of AI in this study differs from the notion of AI typically conveyed in the media and press.

AI has knocked on the doors of enterprises in different sectors as a critical technology (Dwivedi et al., 2019b; Giri et al., 2019; Bottani et al., 2019; Choy et al., 2003). According to Paschen et al. (2020a), the business value generated by AI will reach \$3.9tn in 2022, while it was \$1.2tn in 2018 - increased by over 70\% from 2017. Notably, decision support systems and machine learning techniques are two of the most representative technologies in AI for companies (Duan et al., 2019; Bohanec et al., 2017a; Gentner et al., 2018; Lu et al., 2019). On the one hand, decision support systems are usually applied in companies at the commercial level for supporting managerial decision-making. The implementation of decision support systems usually involves analytical models (Chan and Ip, 2011; Duan et al., 2019), and can be automatized or operated by managers, or a blend of both (Chang et al., 2019; Choi et al., 2016; Lin et al., 2019). On the other hand, machine learning refers to an analytical approach by which embedded algorithms are built to conduct the given task without human interaction. The algorithm learns from the patterns in historical data (Duan et al., 2019). In this way, analytical models based on historical data are established to determine unknown patterns and to make forecasts. These patterns and forecasts support evidencebased decision making. Overlapping with these two representative technologies are several other technologies such as big data analytics, genetic algorithms, and expert and agent-based systems (Kumar et al., 2016; Dikow et al., 2015; Chan, 2010).

\subsection{AI for B2B marketing innovation}

Rapidly changing customer needs have forced companies to re-evaluate their marketing tactics in today's digital era (Hausman et al., 2005; Gentner et al., 2018). As a result, the implementation of different cutting-edge technologies for innovation in B2B marketing has become a critical research area (Pandey et al., 2020; Brosan, 2012; Kumar et al., 2020). Studies show that AI has provided a novel way for B2B marketers to do business, process information and communicate with customers in almost every field (Gentner et al., 2018; Leung et al., 2020; Pandey et al., 2020). For example, AI can significantly increase the efficiency of the existing processes and has an even more enormous impact by serving as a new general-purpose "method of invention" that can reshape the companies' $R \& D$ process and marketing strategies. Particularly, the 
implications of AI for B2B marketing innovation can be summarised in three categories: helping companies to gain information about their customers, users and external stakeholders.

First, customer information plays a critical role for B2B companies as it is related to the short-term business performance of specific products/services and can be used as an essential resource for enhancing a company's offerings (McColl et al., 2019; Sheikh et al., 2019). AI can help B2B companies to analyse both structured and unstructured customer-generated information (e.g., demographic characteristics and online browsing history) to develop sophisticated profiles of existing or potential customers (Meire et al., 2017; Baesens et al., 2004). Second, user information can be a critical resource for marketing, product innovation and operational improvement (Søilen, 2016; Calosso et al., 2004; Lv and Lin, 2017). For instance, the vast amount of information on social media channels can be captured and analysed by AI in order to generate valuable insights for B2B companies about their users, including their preferences, online behaviours, requirements and attitudes (Søilen, 2016). Third, based on the market orientation paradigm, studies suggest that B2B companies should generate and apply information from external stakeholders, such as policymakers and competitors (Hosseini et al., 2010; Kerkkanen et al., 2012). Hence, the use of AI can enable companies to collect market information for example by harvesting the data generated from different sources (e.g., social media, the Internet of Things and third-party channels) (Wang et al., 2017; Shambour and Lu, 2015; Chan et al., 2016). This can lead to valuable insights for more competitive marketing strategies and more effective product/service innovation (Wang et al., 2017).

\subsection{Bibliometrics research method}

In all disciplines, the sheer quantity of academic research has grown enormously, and scholars may be overwhelmed by the need to keep track of all the studies in their area. According to University World News (2018), there are around 30,000 scientific journals, which publish approximately 2 million research articles every year. Hence, examining and summarising the literature has become critical for enhancing a specific stream of research (Behzadian et al., 2010; Evans and Kowanko, 2000).

Traditionally, two main methods have been used for reviewing and evaluating the scientific literature: the structured literature review (Morioka and de Carvalho, 2016; 
Behzadian et al., 2010) and meta-analysis (Crain and Mahard, 1983; Crain and Mahard, 1983). While a structured literature review enables researchers to manage a diverse range of studies (Morioka and de Carvalho, 2016), the approach tends to be timeconsuming, the volume of examined articles is constrained, and study selection is prone to researchers' biases (Behzadian et al., 2010). In contrast, meta-analysis is a quantitative review method (Crain and Mahard, 1983; Maggin et al., 2011) that is robust in exploring relationships among factors. Nevertheless, it is inherently limited in the type and diversity of studies it can examine (Crain and Mahard, 1983). Therefore, the present study adopts a novel approach, namely bibliometric research methods overcome the challenges (Kumar et al., 2020; Liang and Liu, 2018).

Bibliometric methods are effective ways of evaluating and monitoring dynamic changes in research topics in a given field of study (Ardito et al., 2019; Sun et al., 2014; $\mathrm{Xu}$ et al., 2018). They enable a quantitative perspective and examine the scientific impact and quality of studies and resources (Lacka et al., 2020; Liang and Liu, 2018). Compared with other approaches, bibliometrics allows the analysis of any studies as long as their composite elements are related (Ardito et al., 2019). Also, the bibliometric analysis generally focuses more on the macro level and tries to determine hidden patterns in studies. In this way, while conventional methods of literature review can offer in-depth analysis, bibliometric approaches can deal with a broader range and larger number of studies (into the hundreds or even thousands) (Xu et al., 2018). Additionally, the use of the bibliometric approach can minimise researcher bias and effectively takes the perspective of the research community as a whole (Fernandez et al., 2019). Thus, it has been increasingly applied to map the development of specific scientific fields. It also lends itself well to the graphical depiction of its findings (Feng et al., 2017; Liang and Liu, 2018). Besides, the use of bibliometric analysis has been previously applied within operations and marketing (Fernandez et al., 2019; Xu et al., 2018), customer behaviour research (Leung et al., 2017), information technology management (Lacka et al., 2020) and innovation management (Ardito et al., 2019) but not yet to the use of $\mathrm{AI}$ in a $\mathrm{B} 2 \mathrm{~B}$ marketing innovation context.

\section{Research methodology}

3.1. Defining the appropriate search terms

A bibliometric analysis was conducted to address the research questions. The 
terms used in this study cover two cross-disciplinary elements: AI and B2B marketing. It was necessary to include the keywords associated with each element to ensure that all the aspects could be captured. Also, this study considers the third element as innovation related keywords. The three strings and sets of keywords are shown in Table 1. These keywords were identified by the authors after a preliminary survey of key relevant articles.

Table 1: The search string and keywords

Keywords relating to artificial intelligence: (artificial intelligence) OR (machine learning) OR (algorithms) OR (decision support system) OR (business intelligence) OR (business analytics)

AND

Keywords relating to business-to-business marketing: (business-to-business marketing) OR (b2b marketing) OR (business-to-business) OR (b2b) OR (industrial marketing) OR (relationship marketing)

AND

Keywords relating to innovation: (innovation) OR (innovator) OR (Idea) OR (invention)

\subsection{Search results}

A three-step approach was conducted to determine relevant articles systematically. First of all, Scopus and WoS databases were selected for the search. Their key advantage is their comprehensive coverage of relevant studies (Xu et al., 2018; Sun et al., 2014). Follow the approaches suggested by Ramons-Rodriguez and Ruiz-Navarro (2004), this study examines only published journal articles and excludes books, book chapters and conference papers. The search initially had a free time setting such that it would include as many articles as possible up to March 2021. This generated 1128 articles in total (859 articles in Scopus and 269 articles in WoS). All the results were saved in multiple formats (e.g., CVS, TXT and DOC), including all the essential information such as titles, author names, affiliations, keywords and abstracts.

The second step was to eliminate duplicate and irrelevant articles. The articles were screened by examining their titles and abstracts and applying a series of inclusion and exclusion criteria (see Table 2). These criteria were identified based on the research context and previous studies (Kumar et al., 2020; Xu et al., 2018). This left 304 articles for the third step of selection. 
Table 2: Inclusion and exclusion criteria in the refinement

\begin{tabular}{lll}
\hline Inclusion criteria & Exclusion criteria \\
\hline - Focus on the use of artificial & - & Artificial intelligence not related to business- \\
intelligence for innovation in & to-business marketing innovation; \\
business-to-business marketing; & - & Business-to-business marketing activities not \\
- Peer-reviewed journal paper in & related to the use of artificial intelligence; \\
English. & - Non-English language journals.
\end{tabular}

Finally, the authors prepared a table that included all 304 articles and a column to record whether each article should be included or excluded, or whether the authors were unsure, based on a full-text evaluation of its topic and research context. Differences were resolved through discussion. This led to a final sample of 221 articles for the bibliometric analysis. Figure 1 shows a summary of the data sampling process.

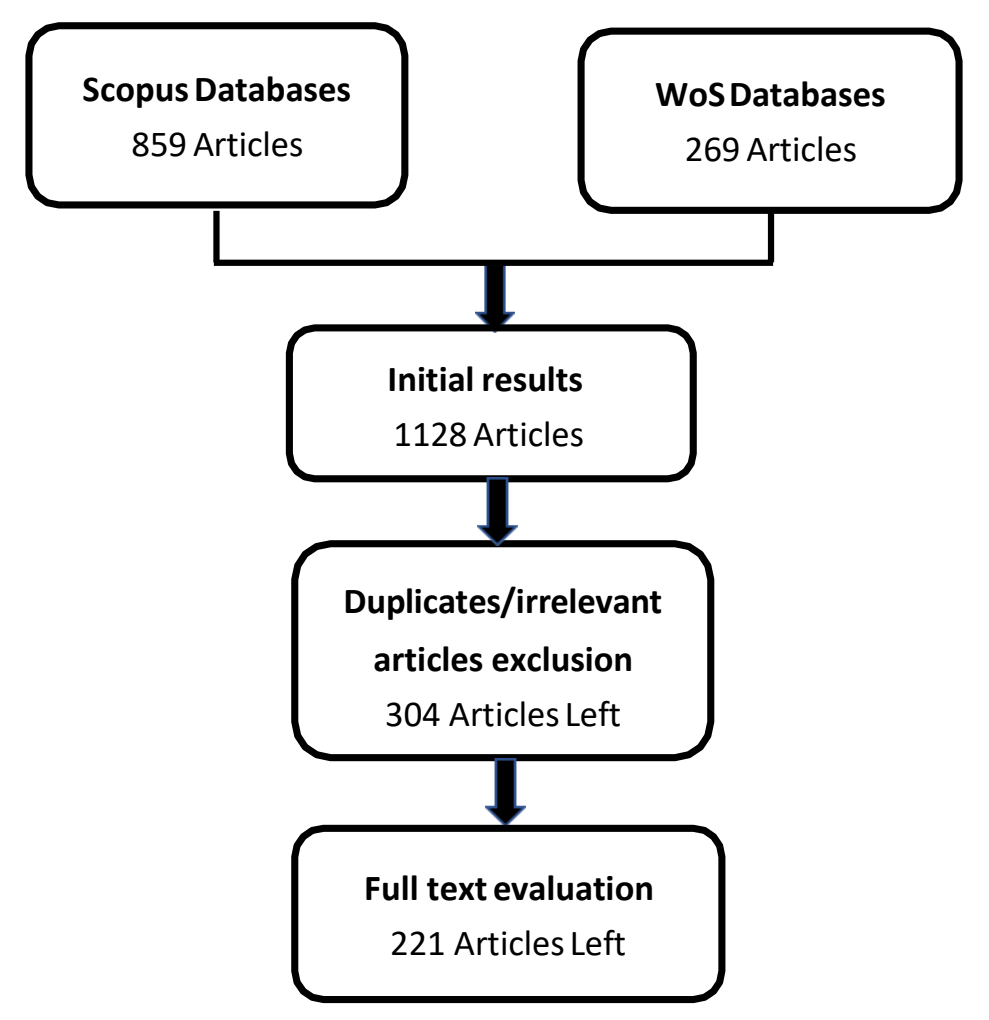

Figure 1: Article Screening Process

\subsection{Descriptive analysis}

Overall, the 221 journal articles were published from 1990 to 2021. Figure 2 shows the upward trend in the number of articles published per year since 2000. Thus, while 
the research topic of $\mathrm{AI}$ in $\mathrm{B} 2 \mathrm{~B}$ marketing innovation has been discussed for a long time, it started to increase in popularity only after 2000. This is not surprising as the beginning of the $21^{\text {st }}$ century marked the start of an era of rapid development in IT technology, the Internet and online commerce. Accordingly, both AI technologies and B2B marketing activities grew fast after 2000.

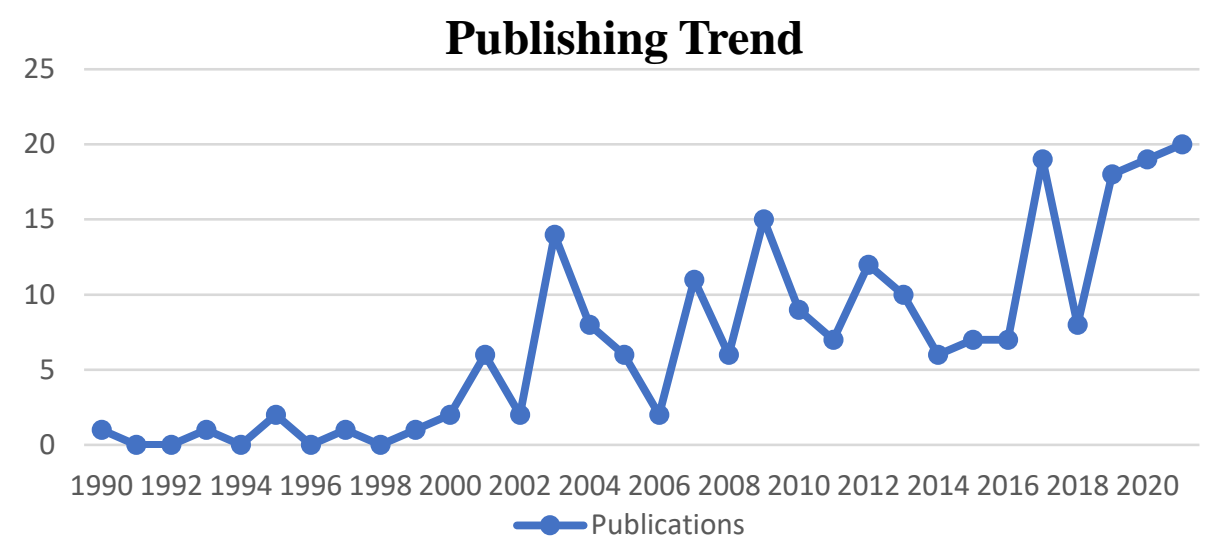

Figure 2: Publishing trend between 1990 and $2021(\mathrm{~N}=221)$

To determine the impact of particular journals, VOSviewer was applied to formulate a bibliometric coupling graph of various journal sources. VOSviewer is a bibliometric analysis tool which is extensively used by the research community to generate bibliographic couplings (Kumar et al., 2020; Ardito et al., 2019; Sun et al., 2014). As Figure 3 displays, journals with significant influence can be categorised into three different clusters, here coloured red, green and blue. Journals in the same cluster belong to the same research field and frequently cite each other (Ardito et al., 2019; Fernandez et al., 2019).

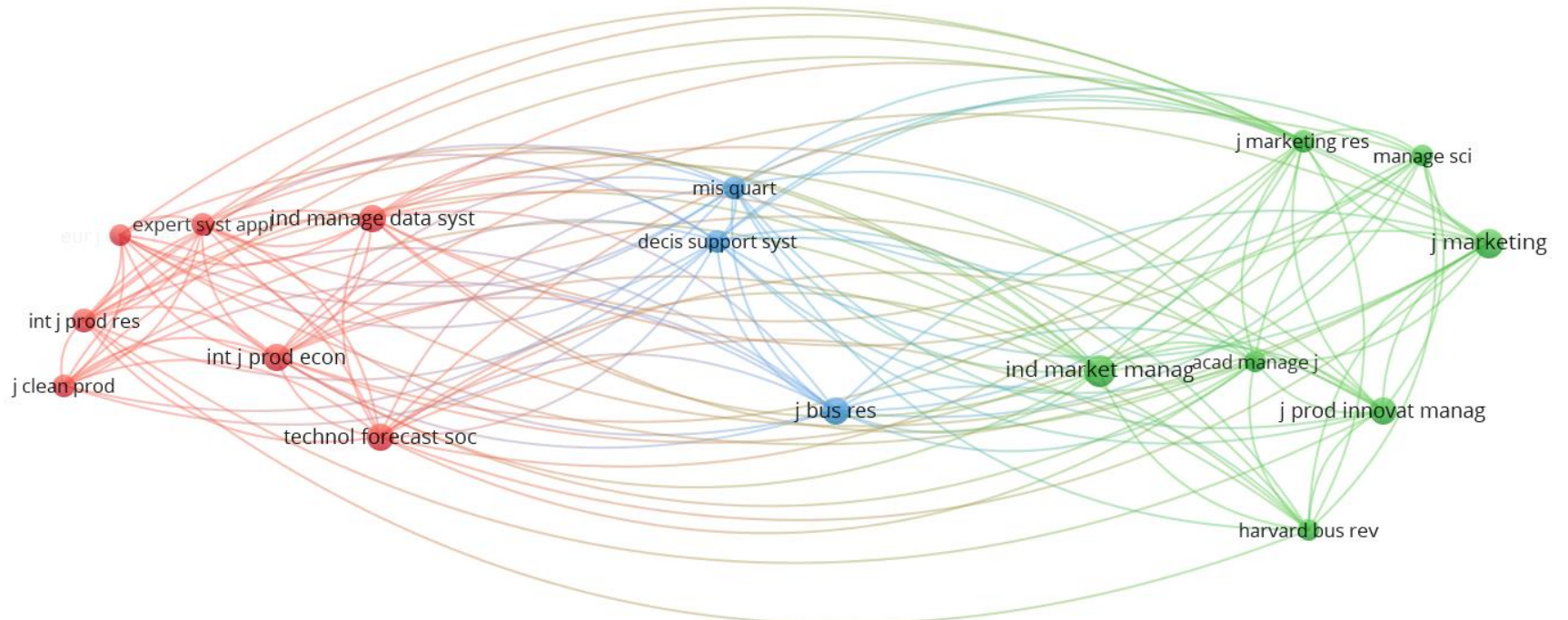

Figure 3: Bibliometric coupling of journal sources 
The journals are connected by links within and between clusters, and the distance between circles (journals) indicates the level of connection (e.g., a shorter distance indicates a stronger connection between two journals). Moreover, the size of circles indicates the influence of journals in terms of their citations (Ardito et al., 2019; Fernandez et al., 2019). It is evident that the Industrial Marketing Management, Industrial Management \& Data Systems contribute the most on the topic of AI and B2B marketing-related research, followed by Technological Forecasting and Social Change, Journal of Product Innovation Management and Decision Support System.

\section{Bibliometric and network analysis}

\subsection{Bibliometric analysis}

The bibliometric analysis provides a statistical evaluation of published scientific articles (Riley and Kleist, 2005; Fernandez et al., 2019). Its three main categories of findings are regarding author influence, affiliation statistics and keywords statistics.

Author influence. To identify the most influential authors, an analysis was performed based on the frequency of authors' names (Sun et al., 2014). Table 3 lists the top 10 contributing authors based on their citations of relevant publications identified in our database. The table shows that the citations are lower than 1,000 for most of the authors, indicating that this area is still lacking specialists. This, in turn, suggests that the research field of AI in B2B marketing innovation is still at an early stage and has enormous potential to be explored by researchers.

Table 3: Top 10 contributing authors

\begin{tabular}{lc}
\hline \multicolumn{1}{c}{ Author } & Citations in this field \\
\hline Van der aalst, W.M & 1466 \\
Li, S & 560 \\
Bohanec, M & 236 \\
Robnik-Šikonja, M & 236 \\
Borštnar, M.K & 236 \\
Zahay, D & 192 \\
Griffin, A & 192 \\
Cantamessa, M & 187 \\
Calosso, T & 187 \\
Paschen, J & 177 \\
\hline
\end{tabular}


Affiliation statistics. The affiliation statistics of authors were extracted to identify the countries in which they were located. Figure 4 shows the results but displays only countries with significant influence. The results suggest that institutions from the United States have the most impact on this research topic. This is not surprising, as the United States has been a leader in the development of AI (Paschen et al., 2019). Meanwhile, institutions from China, Hong Kong and the United Kingdom also have a good reputation and large influence in this field.

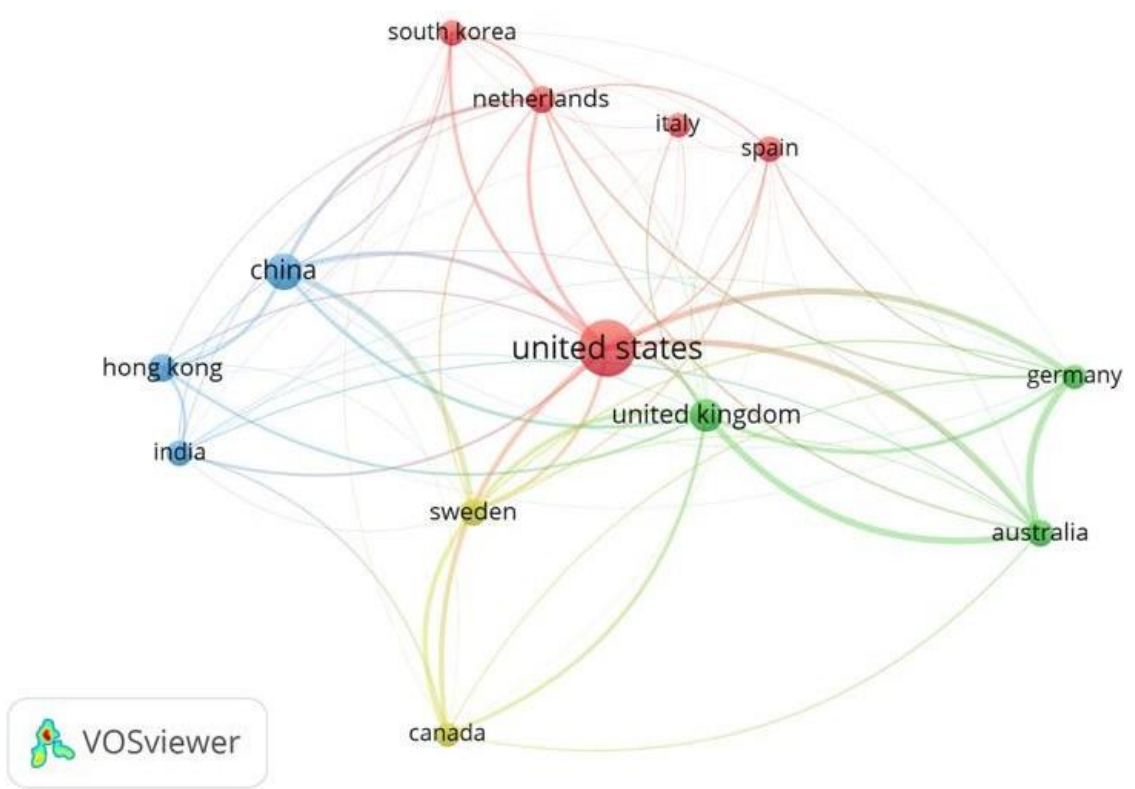

Figure 4: Bibliographic coupling of contributing countries

\subsection{Network analysis}

A network analysis was performed to complement the bibliometric analysis to identify connections among different articles and social structures that underpin these connections (Pandey et al., 2020). Specifically, citation, PageRank and co-citation analyses were conducted based on the topical classification of the 221 articles.

Citation analysis. To evaluate the significance of publications, an analysis of citation numbers was performed based on Google Scholar citations (Leung et al., 2017; Riley and Kleist, 2005; Ardito et al., 2019). Table 4 lists the 10 articles most frequently cited. Particularly, the most cited paper describes a logical and intelligent system for strategic marketing analysis ( $\mathrm{Li}, 2000)$. This is followed by a paper on the application of artificial neural networks to the industrial marketing segmentation problem (Fish et al., 1995). The third most frequently cited paper develops a decision support system 
and uses customer purchasing behaviour together with product sales data to predict the net customer lifetime value (Chan and Ip, 2011). All these papers focused on developing novel $\mathrm{AI}$ technologies for $\mathrm{B} 2 \mathrm{~B}$ marketing innovation. The top ten papers were cited from 29 to 158 times, indicating that the topic is still in its infancy. 
Table 4: Top 10 papers based on their citation

\begin{tabular}{|c|c|c|c|}
\hline Author & $\begin{array}{l}\text { Publication } \\
\text { year }\end{array}$ & Paper title & $\begin{array}{l}\text { Global } \\
\text { citation }\end{array}$ \\
\hline Zahay, D. and Griffin, A. & 2004 & $\begin{array}{l}\text { Customer learning processes, strategy selection, and performance in business-to- } \\
\text { business service firms. }\end{array}$ & 192 \\
\hline Hsu, L.L. and Chen, M. & 2004 & $\begin{array}{l}\text { Impacts of ERP systems on the integrated-interaction performance of } \\
\text { manufacturing and marketing. }\end{array}$ & 171 \\
\hline $\mathrm{Li}, \mathrm{S}$ & 2000 & The development of a hybrid intelligent system for developing marketing strategy. & 161 \\
\hline $\begin{array}{l}\text { Fish, K.E., Barnes, J.H. and } \\
\text { AikenAssistant, M.W. }\end{array}$ & 1995 & Artificial neural networks: a new methodology for industrial market segmentation. & 157 \\
\hline Chan, S.L. and Ip, W.H. & 2011 & $\begin{array}{l}\text { A dynamic decision support system to predict the value of customer for new } \\
\text { product development. }\end{array}$ & 140 \\
\hline Martínez-López, F.J. and Casillas, J. & 2013 & $\begin{array}{l}\text { Artificial intelligence-based systems applied in industrial marketing: An historical } \\
\text { overview, current and future insights. }\end{array}$ & 114 \\
\hline Wu, D., Zhang, G. and Lu, J. & 2015 & $\begin{array}{l}\text { A fuzzy preference tree-based recommender system for personalized business-to- } \\
\text { business e-services. }\end{array}$ & 99 \\
\hline Li, S., \& Li, J. Z. & 2009 & $\begin{array}{l}\text { Hybridising human judgment, AHP, simulation and a fuzzy expert system for } \\
\text { strategy formulation under uncertainty. }\end{array}$ & 96 \\
\hline $\begin{array}{l}\text { Calosso, T., Cantamessa, M., Vu, D. } \\
\text { and Villa, A. }\end{array}$ & 2003 & $\begin{array}{l}\text { Production planning and order acceptance in business to business electronic } \\
\text { commerce. }\end{array}$ & 75 \\
\hline $\begin{array}{l}\text { Paschen, J., Kietzmann, J. and } \\
\text { Kietzmann, T.C. }\end{array}$ & 2019 & $\begin{array}{l}\text { Artificial intelligence }(\mathrm{AI}) \text { and its implications for market knowledge in } \mathrm{B} 2 \mathrm{~B} \\
\text { marketing. }\end{array}$ & 66 \\
\hline
\end{tabular}


PageRank analysis. To supplement the citation analysis, a PageRank analysis was performed as a measure of both the prestige and the popularity of the articles (Bolle et al., 2006; Kumar et al., 2020). The PageRank analysis was developed to prioritise web information when a keyword is entered into a search engine (Liang and Liu, 2018). Thus, it can not only be used to find the connectivity between web pages but also to identify the citation connection among different articles. For instance, suppose article A has been cited by articles $Y 1, Y 2, Y 3 \ldots, Y n$, where article $Y i$ has citations $C(Y i)$. Under this circumstance, the PageRank of article $A$ (represented by $P R(A)$ ) in a network of $N$ articles, can be determined as:

$$
P R(A)=\frac{(1-d)}{N}+d\left(\frac{P R\left(Y_{1}\right)}{C\left(Y_{1}\right)}+\cdots+\frac{P R\left(Y_{n}\right)}{C\left(Y_{n}\right)}\right)
$$

the parameter $d$ is a damping ratio, which ranges from 0 to 1 , that indicates the fraction of random walks that keep propagating along with the citations.

The PageRank analysis generates a probability distribution over articles, so the PageRank of all articles can be determined by using an iterative algorithm and the corresponding principal eigenvector of the normalised citation matrix of the articles (Feng et al., 2017; Xu et al., 2018). For citation analysis, the references of an article are captured according to a path of average length 2 (as suggested by Mishra et al., 2018), leading to the parameter $d=0.5$, which has been widely accepted for similar algorithms used for analysing citation networks (Lee et al., 2013). Table 5 lists the top 10 articles based on the PageRank analysis. 91out of 221 articles in our database were co-cited by other studies, and the PageRank values for the articles are between 0.008997 and 0.068655, suggesting the results are significant (Lee et al., 2013; Mishra et al., 2018; Kumar et al., 2020). 
Table 5: Top 10 papers ranked by PageRank

\begin{tabular}{|c|c|c|c|}
\hline Author & $\begin{array}{l}\text { Publication } \\
\text { Year }\end{array}$ & Title & PageRank \\
\hline Zahay, D. and Griffin, A. & 2004 & $\begin{array}{l}\text { Customer learning processes, strategy selection, and performance in business-to- } \\
\text { business service firms. }\end{array}$ & 0.068655 \\
\hline Wilson, R.D. and Bettis-Outland, H. & 2019 & $\begin{array}{l}\text { Can artificial neural network models be used to improve the analysis of B2B } \\
\text { marketing research data? }\end{array}$ & 0.03574 \\
\hline Yin, J., Cao, B., Deng, S. and Wu, Z. & 2012 & Process Discovery from the Log of Business Rule Engine. & 0.028856 \\
\hline $\begin{array}{l}\text { Steinhoff, L., Arli, D., Weaven, S. and } \\
\text { Kozlenkova, I.V. }\end{array}$ & 2019 & Online relationship marketing. & 0.027465 \\
\hline Wang, Y., Rod, M., Deng, Q. and Ji, S. & 2020 & $\begin{array}{l}\text { Exploiting business networks in the age of social media: the use and integration } \\
\text { of social media analytics in B2B marketing. }\end{array}$ & 0.026203 \\
\hline Pandey, N., Nayal, P. and Rathore, A.S. & 2020 & $\begin{array}{l}\text { Digital marketing for B2B organizations: structured literature review and future } \\
\text { research directions. }\end{array}$ & 0.020403 \\
\hline $\begin{array}{l}\text { Teich, J.E., Wallenius, H., Wallenius, J. } \\
\text { and Koppius, O.R. }\end{array}$ & 2004 & Emerging multiple issue e-auctions. & 0.017843 \\
\hline $\begin{array}{l}\text { Paschen, J., Paschen, U., Pala, E. and } \\
\text { Kietzmann, J. }\end{array}$ & 2020 & $\begin{array}{l}\text { Artificial intelligence (AI) and value co-creation in B2B sales: Activities, actors } \\
\text { and resources. }\end{array}$ & 0.017315 \\
\hline Wierenga, B. and Ophuis, P.A.O. & 1997 & Marketing decision support systems: Adoption, use, and satisfaction. & 0.016527 \\
\hline Xia, M., Stallaert, J. and Whinston, A.B. & 2005 & Solving the combinatorial double auction problem. & 0.015385 \\
\hline
\end{tabular}


Co-citation analysis. Co-citation analysis constructs a set of nodes representing the journal papers and links to show their co-citation in other articles (Lee et al., 2013). We say two journal articles are co-cited if each is listed in the other's references. Data clustering or data modularity can be adopted as a classification method for categorising a given set of articles (Fernandez et al., 2019). This enables a concept analysis of co-citation networks, determining key themes, interrelationships and hidden patterns (Leung et al., 2017; Sun et al., 2014; Lacka et al., 2020). In this way, the nodes generated in a co-citation network can be categorised into clusters based on the density or strength of links between nodes (Liang and Liu, 2018; Xu et al., 2018, Mishra et al., 2018).

The most commonly used algorithm for data clustering is the Louvain algorithm, which is an iterative optimisation model for identifying the number of partitions that maximises the index of modularity (Mishra et al., 2018; Riley and Kleist, 2005). The index of modularity is a scalar measure ranging from -1 to +1 that evaluates the density of edges within clusters against edges between clusters (Kumar et al., 2020). According to Mishra et al. (2018), for weighted networks, the index of modularity, $Q$, can be determined as:

$$
Q=\frac{1}{2 m} \sum_{i j}\left[A_{i j}-\frac{k_{i} k_{j}}{2 m}\right] \delta\left(c_{i}, c_{j}\right)
$$

where $A i j$ is the weight of the link between nodes $\mathrm{j}$ and $\mathrm{i}, k i$ is the total weight of the links associated with node $\mathrm{i}\left(k i=\sum_{i} A_{i j}\right)$, and $c i$ is the cluster to which vertex $\mathrm{i}$ is allocated; $\delta(\mathrm{u}$, v) will be 1 as long as $\mathrm{u}=\mathrm{v}$ and 0 otherwise. Additionally, $m=\left(\frac{1}{2}\right) \sum_{i j} A_{i j}$, which indicates the total weights of all the links, as each link is examined twice when all the $A_{i j}$ are added up.

To generate the results effectively, the Louvain algorithm keeps iterating two steps: 1) every node in the network is allocated to a random cluster, and for node $i$ the gain in modularity is calculated when it is eliminated from its cluster (Bolle et al., 2006); and 2) node $\mathrm{i}$ is allocated to different clusters until the maximum gain in modularity is achieved (Liang and Liu, 2018) (otherwise, node i remains in its original cluster). The iteration ends when the modularity value reaches a local maximum (Ardito et al., 2019). By performing the analysis, the pre-identified 91 articles (nodes) lead to the determination of five different clusters (See Table 6 below). These clusters are further explained and discussed in the next section. 
Table 6: A summary of cluster analysis: Top 10 articles based on its PageRank values

\begin{tabular}{|c|c|c|c|c|}
\hline Cluster 1 & Cluster 2 & Cluster 3 & Cluster 4 & Cluster 5 \\
\hline Zahay and Griffin (2004) & Bohanec et al. (2017a) & Teich et al. (2004) & $\mathrm{Xu}$ and Wang (2002) & Steinhoff et al. (2019) \\
\hline $\begin{array}{l}\text { Moliner-Velazquez et al. } \\
(2014)\end{array}$ & Fillmore (2010) & Paschen et al. (2020a) & $\begin{array}{l}\text { Van Loon and Van } \\
\text { Wassenhove }(2018)\end{array}$ & Paschen et al. (2019) \\
\hline Vincent (2017) & Leung et al. (2019) & Xia et al. (2005) & $\begin{array}{l}\text { Van Der Aalst et al. } \\
(2007)\end{array}$ & $\begin{array}{l}\text { Wierenga and Ophuis } \\
\text { (1997) }\end{array}$ \\
\hline Baesens et al. (2004) & Kerkkanen et al. (2012) & Teich et al. (1999) & Li et al. (2003) & Pathak and Zeng (2003) \\
\hline Chang et al. (2008) & Fu et al. (2017) & Paschen et al. (2020b) & De Heer (2003) & Prior and Keränen (2020) \\
\hline Hausman et al. (2005) & Dong et al. (2014) & Xu and Huang (2017) & Park and Park (2003) & $\begin{array}{l}\text { Kot and Leszczyński } \\
(2020)\end{array}$ \\
\hline Meire et al. (2017) & Shambour and Lu (2015) & Sen et al. (2020) & Choi and Kim (2008) & $\begin{array}{l}\text { Klimanov and Tretyak } \\
\text { (2019) }\end{array}$ \\
\hline Tsafarakis et al. (2013) & Noori (2013) & Lee and Kwon (2008) & Jooste and Vlok (2015) & Bohanec et al. (2017c) \\
\hline Schaeffer and Sanchez (2020) & Bohanec et al. (2018) & Leskelä et al. (2007) & $\begin{array}{l}\text { Dadouchi and Agard } \\
\text { (2018) }\end{array}$ & Giri et al. (2019) \\
\hline Sheikh et al. (2019) & Bohanec et al. (2017b) & Chiu et al. (2005) & Biehl and Kim (2003) & $\begin{array}{l}\text { Ozturk and Karabat1 } \\
\text { (2017) }\end{array}$ \\
\hline
\end{tabular}




\section{Findings}

The results indicate the presence of five different clusters, which can be interpreted as domains in which the analysed articles appear. While there is broad consensus on the central theme of each cluster, the clustering results may seem fuzzy; nevertheless, the analysis identifies the central themes regarding the implementation of $\mathrm{AI}$ as an enabler for innovation in B2B marketing from diverse perspectives.

\subsection{AI-enabled customer relationship management in B2B marketing}

There are 23 articles in this cluster, focusing on explaining the implementation of AI technologies for innovative customer relationship management (CRM). According to Meire et al. (2017), CRM refers to a managerial strategy which evaluates the business interaction with consumers by combining customer management technologies and business operations processes. Studies suggest that AI as an innovative method can help marketers to gain valuable information from customers, keep existing customers and increase their satisfaction (Meire et al., 2017; Tsafarakis et al., 2013; Baesens et al., 2004; Hosseini et al., 2010; Castellano and Del Gobbo, 2018). Compared to traditional CRM, AI-enabled technologies allow B2B managers to gain more accurate customer related innovation for keeping their existing customers as well as exploring the opportunities for more potential new customers (Baesens et al., 2004; Ahn et al., 2003).

The articles in this cluster show that AI technologies can help companies to gain comprehensive and useful insights for innovation from the massive information pool on customers (Zahay and Griffin, 2004; Schaeffer and Rodriguez Sanchez, 2020). For instance, Zahay and Griffin (2004) develop a novel measurement system based on organisational learning theory for handling a wide range of customer information. This process can be seen as a customer learning process which allows marketers to gain knowledge and summarise hidden patterns within customer information. Moreover, studies also illustrate that B2B marketers can use AI to help them keep their existing valuable customers (Baesens et al., 2004; Schaeffer and Sanchez, 2020; Moghaddam et al., 2017). According to Chang et al. (2008), obtaining new consumers is many times more expensive than retaining business with existing consumers. Therefore, B2B marketers should concentrate on maintaining customers' loyalty through AI technologies. For instance, Baesens et al. (2004) studied various Bayesian network classifiers and determined an innovative model that can be used to present customers' long-term loyalty lifecycle. In this way, AI can help managers to devise 
better strategies to satisfy and keep their valuable customers.

It is documented that the implementation of AI for innovation can significantly improve customer satisfaction in B2B marketing (Moghaddam et al., 2017; Joh and Lee, 2003; Zahay and Griffin, 2004). Indeed, customer satisfaction is one of the most critical indicators of CRM, and AI technologies often take less time to improve customer satisfaction compared with the conventional management processes (Meire et al., 2017; Moghaddam et al., 2017; Baesens et al., 2004). For example, Moghaddam et al. (2017) develop a novel model (i.e., RFMV) to classify customers into different groups based on different criteria. In this way, B2B marketers can understand their customers and personalise the company's services in order to increase customer satisfaction.

\subsection{B2B sales forecasting through AI}

This cluster contains 11 articles. Accurate and rapid sales forecasting enables companies to make the right business decisions and achieve better business performance (Sohrabpour et al., 2021; Bohanec et al., 2017a). However, forecasting is not easy, as it can be influenced by diverse interrelated elements such as the conflict interests of participants, the dynamic business environment and multiple stages of sales (Fu et al., 2017; Fillmore, 2010). Accordingly, AI technologies can be applied as a new way to overcome the challenges by analysing various information such as companies' past sales records, economic trends and industry-wide comparisons (Bohanec et al., 2017b; Kerkkanen et al., 2012; Dong et al., 2014; Leung et al., 2019).

Studies in this cluster primarily focus on the innovative use of intelligent sales forecasting systems which can not only study the past sales data but also serve real-time sales data as feedback to improve the accuracy of predictions. For instance, Bohanec et al. (2017a) develop a machine learning model to use B2B marketers' past data as inputs for the development of classification models, then verify the results of the models, and use those results to improve marketing decisions. New findings and feedback generated will be fed back into the models for further enhancement. Also, the use of AI can help B2B marketers by minimising bias and subjectivity, in that it can provide an entirely objective analysis (Dong et al., 2014). Such a data-based decision model can comprehensively support the interactive evaluation of marketers' decisions within the dynamic business environment. Additionally, AI technologies have become essential for B2B sales forecasting with the development of e-commerce (Leung et al., 2019; Kerkkänen et al., 
2012). The online market allows B2B marketers potentially to reach billions of consumers without any boundaries. However, the vast amount of information would be impossible for marketers to understand and process. As a result, AI has become an innovative tool for sales forecasting in B2B e-commerce (Shambour and Lu, 2015; Fillmore, 2010). Leung et al. (2019) developed a pricing decision support system named Smart-Quo for the B2B online market. This system analyses the sales records and past pricing data to forecast future sales. By using this AI system, the best pricing decision can be generated and provided to marketers in real-time.

\subsection{AI for value co-creation in $\mathrm{B} 2 \mathrm{~B}$ marketing}

This cluster contains 22 articles. These studies indicate that AI-enable technologies provide business participants an unique way for exchanging knowledge, information and resources. Notably, the AI value co-creation process involves three types of actor - 'bot', 'curators' and 'consumers'. The 'bot' represents the data collection and analysing algorithms. The 'curators' represents employees who provide support services such as knowledge creation and information management to the end-users. The 'consumers' are the end-users who get the final information from the 'bot' and 'curators'. These three actors achieve an interlocking, effective and practical AI value co-creation process in B2B marketing (Paschen et al. 2020a).

Regarding the articles in this cluster, e-auction and e-negotiation are two innovative approaches for value co-creation by using AI technologies. The B2B e-auction is one of the important ways to co-create value between participants, whereby both sellers and buyers can sell or get products at their expected profit and price (Teich et al., 1999). For instance, Sen et al. (2020) provide a decision support approach for bidders to offer real-time information feedback on multi-unit e-auction platforms. It overcomes a critical challenge with live information and memory requirements in procurement and sales processes in $\mathrm{B} 2 \mathrm{~B}$ marketing. Besides, the high-quality B2B negotiation process can significantly benefit from the implementation of AI technologies (Chiu et al., 2005; Calosso et al., 2004; Lee and Kwon, 2008). Specifically, AI technologies can be applied in B2B negotiation processes for avoiding mistakes, improving the quality of cooperation and promoting efficiency (Wilson and Bettis-Outland, 2019). For example, Chiu et al. (2005) develop a meta-model for enegotiation. In a B2B context, this model can be used to protect the negotiation process within a systematically supported environment to achieve both efficient negotiation and 
satisfying results.

\subsection{AI-enabled operations management in $\mathrm{B} 2 \mathrm{~B}$ marketing}

Cluster 4 consists of 17 articles on the implementation of AI-enabled decision support systems or algorithms for innovation in different parts of operations management. Operations management has been identified as end-to-end organisational business management service chains which include many activities, such as product design, product manufacturing, strategy planning, delivery service, logistics, customisation and outsourcing (Dadouchi and Agard, 2018; Park and Park, 2003). Today, AI-enabled technologies change the traditional process model of operations management and create digital business models which are more competitive in the current market.

In the era of digitalisation, AI is like the new electricity and data is like the new oil, and both are needed in different activities of operations management. For instance, workflow management comprises the design and implementation of workflows according to the company's needs and goals. Thus, $\mathrm{Xu}$ and Wang (2002) propose a collaborative multi-agent system which can identify problems with workflows and solve them. As a result, this intelligent system can respond to business regulations asking for re-organisation of the workflow, re-arranging the transaction and procurement process for highly efficient workflow management. Moreover, inventory management is a crucial part of operations and supply chain management (Dadochi and Agard, 2018; Wilson and Bettis-Outland, 2019). In particular, the variability in product demand is one of the important sources of uncertainty in supply chain management. To address this issue, Dadouchi and Agard (2018) propose an algorithm for analysing the effect of stock levels on product recommendation. It enables companies to manage the demand for specific items from particular consumers. Furthermore, merchandise management also plays a vital role in operations management, especially in the retail industry (De Heer, 2003; Park and Park, 2003). Accordingly, Park and Park (2003) develop an AI system which can conduct merchandise management efficiently, autonomously and in a timely manner. Compared with traditional merchandise management systems, an AI system can bring high-class merchandise management with lower inventory levels and greater sales and profits. Last but not least, some articles in this cluster pay attention to the selection of suppliers and vendors in e- procurement management. For instance, Choi and Kim (2008) present a two-stage decision support system for hybrid e-procurement management. This system enables buyers to specify their 
requirements more precisely and choose the best suppliers to fulfil those requirements.

\subsection{Conceptual frameworks for $\mathrm{AI}$ in $\mathrm{B} 2 \mathrm{~B}$ marketing}

Cluster 5 has 18 articles, generally offering an overview of different conceptual frameworks for supporting the use of $\mathrm{AI}$ as an enabler for innovation in $\mathrm{B} 2 \mathrm{~B}$ marketing. According to Daskou and Mangina (2003), conceptual frameworks are structures which scholars believe can best summarise the natural progression of the phenomenon investigated.

Most of these articles use a comprehensive literature review to develop their frameworks. Pandey et al. (2020) supplement their systematic literature review on B2B digital marketing with semi-structured interviews with B2B digital marketing professionals. Their analysis produced an innovative framework to help companies align their digital marketing strategies with changing B2B market dynamics, by developing a decision support system, paying attention to value co-creation and exploiting the capability of social media applications. Paschen et al. (2019) propose a novel framework to explain the use of AI as a series of building blocks. Their article systematically discusses the implementation of AI in relation to three different kinds of market knowledge (i.e., user knowledge, external marketing knowledge and customer knowledge) within a B2B marketing environment. Daskou and Mangina (2003) formulate an unique framework of a new AI system designed for integrating customer surveys and a database of customer loyalty programs. This model can help companies to establish an information-based connection with both their retailers and their consumers. Many other types of the conceptual framework have been developed (e.g., Ozturk and Karabti, 2017; Wang et al., 2017, Wang et al., 2020a, Martínez-López and Casillas, 2013) and in this cluster the subject of AI in B2B marketing has been examined from diverse perspectives.

\section{Research trends and future directions}

To identify trends in the literature, as well as to determine likely the future directions of research on AI-enabled B2B marketing innovation, this study uses Leximancer to conduct a content analysis. Leximancer applies a Bayesian learning algorithm to analyse the proximity values of textual data. Concepts and themes are the main outputs (Kumar et al., 2020). It uses articles' information as input and generates concept maps describing key 
themes and linkages among them. In this study, the articles were separated into five groups for the analysis based on their different years of publication: before 2001 (8 articles), 20012005 (37 articles), 2006-2010 (45 articles), 2011-2015 (41 articles) and 2016-2021 (90 articles).

\subsection{Before 2001: The emergence of research on AItechnologies}

This period saw the emergence of AI research within B2B marketing. As shown in Figure 5, the theme 'artificial' is the most important aspect of this research (as indicated by the large size of the circle, coloured red). According to Steinberg and Plank (1990), AI technologies such as knowledge or expert systems began to influence and change B2B marketing decision-making in the early 1900s. The use of AI as an enabler for innovation can not only provide the scientific, operational disciplines for B2B marketing but also significantly improve the efficiency of B2B marketing.

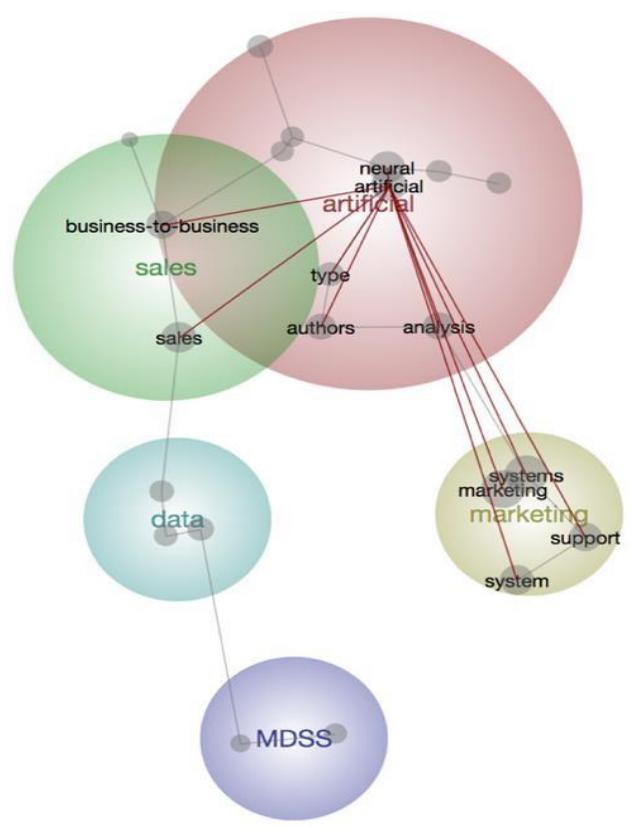

Figure 5: Research themes during the period before 2001

The other themes are less significant. These themes are B2B 'sales' (Fish et al., 1995), 'marketing' (Mentzer and Gandhi, 1993; Li, 2000), 'data' (Michel, 2000) and 'MDSS' (Wierenga and Ophuis, 1997). Interestingly, the theme 'artificial' overlaps with the theme 'sales', indicating that research on these two themes had a robust connection in this period. For example, Fish et al. (1995) suggest that AI can help B2B marketers to extract and analyse the most useful information from the vast data pool, which can help B2B marketers 
obtain useful marketing advice or sales forecasts. Since AI is always more rational in processing and analysing problems than humans, it can also help B2B marketers to make strategies and decisions in a more rational and effective manner (Wierenga and Ophuis, 1997). Overall, artificial technology was the centre of academic research in this period, and researchers started to realise that AI can be used as an enabler for innovation to advise and improve B2B sales in different ways.

\subsection{1-2005: Development of intelligent B2B marketing}

Research in this period indicates the development of intelligent B2B marketing. Compared with the period before 2001, the critical research theme shifted away from AI technologies to B2B marketing. As shown in Figure 6, the theme of B2B 'marketing' was the hottest research topic. This is not surprising, as e-commerce was being increasingly implemented in a variety of business activities during the period (Silverman et al., 2001; Fensel et al., 2001). As a result, interactions between two business partners produced the managerial problems and challenges that AI technologies are well suited to solving (Kuechler et al., 2001).

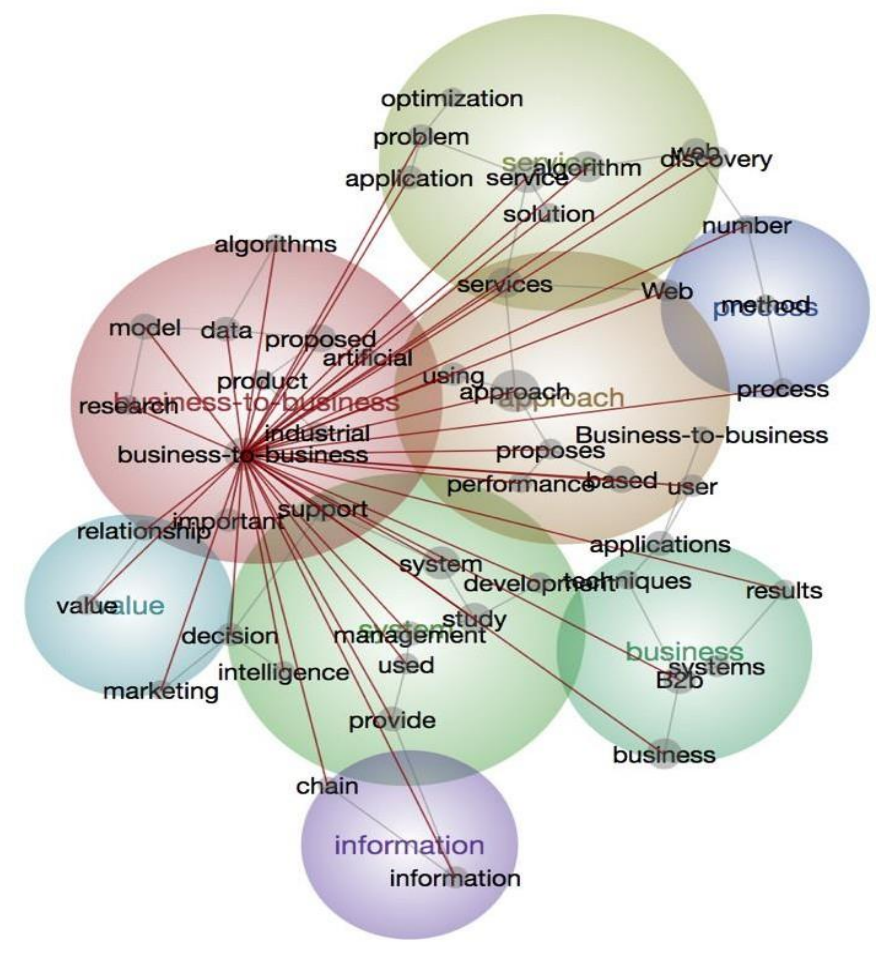

Figure 6: Research themes during the period 2001-2005

Research in this period paid more attention to the support of B2B innovative activities 
from various perspectives through the use of AI technologies. Other themes include 'service' (Chiu et al., 2005; Zahay and Griffin, 2004), 'approach' (Joh and Lee, 2003; Hausman et al., 2005) and intelligent 'system' (Xia et al., 2005; Calosso et al., 2004). Notably, 'approach' and 'system' overlapped with the theme of B2B 'marketing', as they both focus on the development of novel methods to improve B2B marketing. Research on 'intelligence agents' in B2B marketing started to be conducted in this period. An agent-based system can help B2B marketers to evaluate their products' performance, predict the seasonal sales trend and select appropriate merchandise (Daskou and Mangina, 2003; Xia et al., 2005; Park and Park, 2003). In short, the numbers of research themes are much larger than in the preceding period (before 2000), suggesting increasing interactions between B2B marketing innovation and AI technologies. Moreover, the application of AI as an enabler for innovation in the B2B field tended to be more practical during this period.

\subsection{6-2010: Development of B2B support systems}

Research in this period concentrated on the development of B2B support systems, although the primary research theme was still B2B marketing, as in the preceding period (2005-2010). However, intelligent B2B marketing management with most state- of-art technologies was more widely studied (e.g. Van Der Aalst et al., 2007; Lee and Kwon, 2008; Rich and Latusek, 2010). In other words, B2B marketers were not only seeking to adopt AI technologies in general B2B administration but also wanted more value-added services to increase profits (Backhaus et al., 2010). 


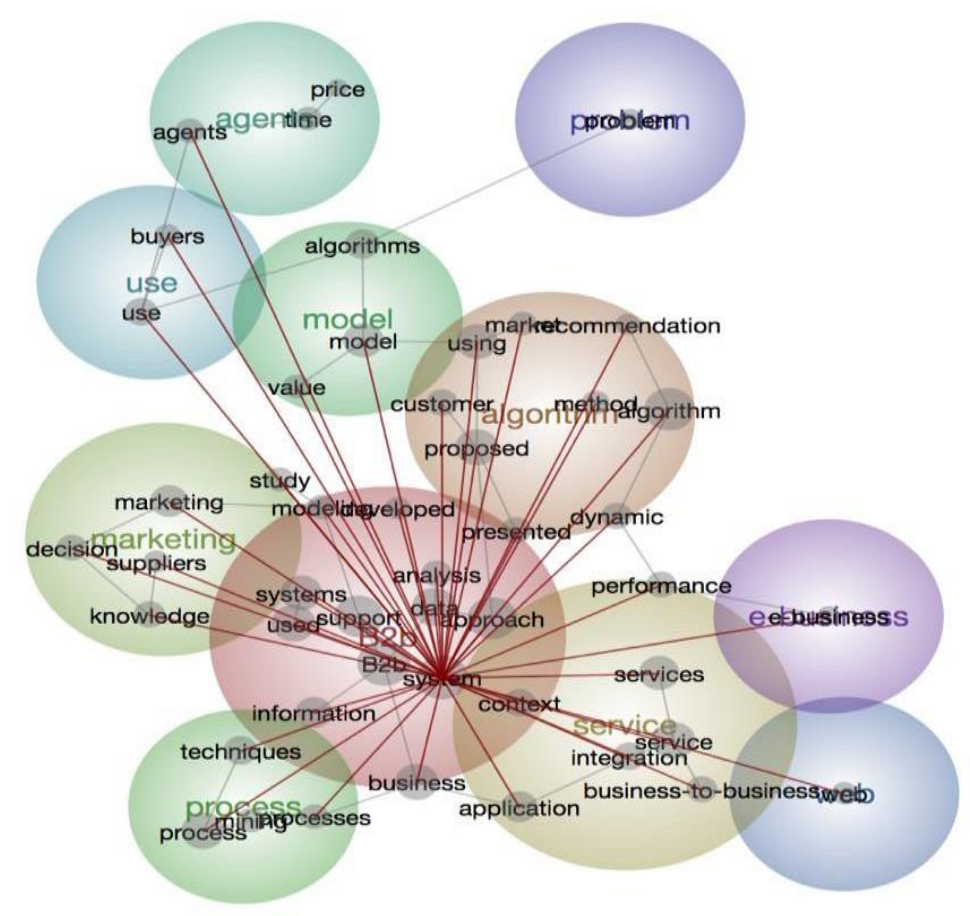

Figure 7: Research themes during the period 2006-2010

Other themes were of less salient, including 'algorithm' (Schellhorn, 2009; Piao et al., 2009), 'service' (Lei et al., 2008; Chun and Wong, 2007) and 'marketing' (Laínez et al., 2010; $\mathrm{Li}$ and $\mathrm{Li}, 2009 ; \mathrm{Li}, 2007)$. As shown in Figure 7, most of these overlap with the major theme 'B2B', indicating they are significantly connected to B2B marketing (e.g., such as adopting novel algorithms to improve B2B marketing services). Among these themes, 'algorithm' is a new one to emerge in the period. Algorithms require both inputs and outputs in order to 'learn' the information or data and formulate the new outputs when given new inputs (Yagüe et al., 2007). Argoneto and Renna (2010) develop an algorithm based on the general emarketplace business model to facilitate trade between sellers and buyers in the B2B context. Piao et al. (2009) propose a new entropy-based algorithm to customise recommendations for B2B e-commerce marketing. Research in this period proposed many new, innovative intelligent algorithms for B2B marketing, and algorithms came to represent AI more widely in the B2B marketing field.

\subsection{1-2015: Discovery of intelligent approaches in B2B marketing}

Research in this period shifts from B2B marketing activities to focus on intelligent approaches. As shown in Figure 8, the theme 'approach' (which incorporates algorithm, 
service support system and problem-solving application) becomes the most important research topic in this period. These studies pay particular attention to the development of advanced, efficient AI approaches to support B2B decision-making. Notably, the price negotiation approach becomes an important area in management and economic science for B2B marketers to gain competitiveness. Fu et al. (2015) proposed a systematic fuzzy approach, which was the first intelligent approach to provide the boundary of a negotiation price by learning and analysing transaction records. That intelligent approach can help managers to improve their pricing strategies by taking account of a wide range of factors, such as consumers' needs, operation costs and companies' demands.

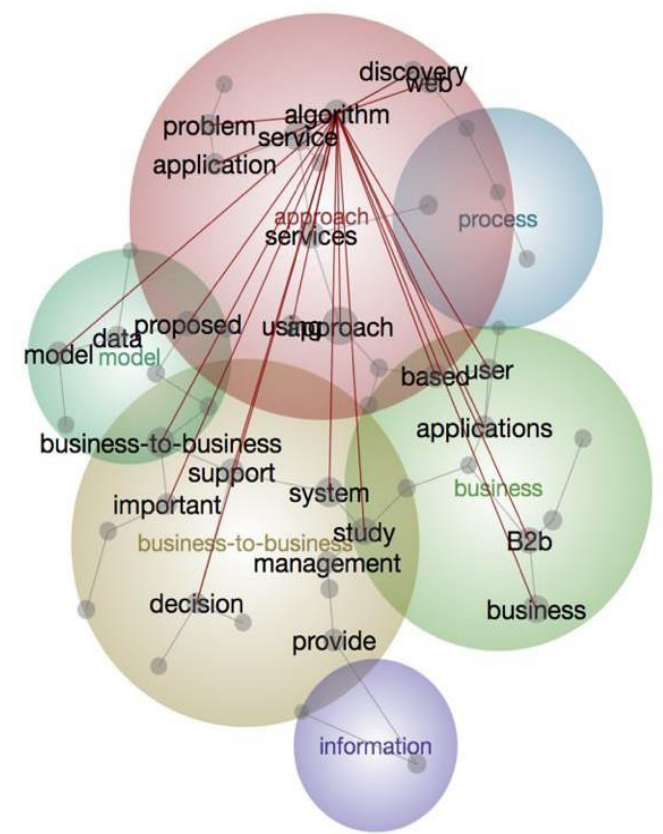

Figure 8: Research themes during the period 2011-2015

Apart from the themes 'approach' and 'business-to-business', themes such as 'process' (Yin et al., 2012; Kerkkanen et al., 2012), 'model' (Paulraj et al., 2012; Hamichi et al., 2013) and 'business' (Demirkan et al., 2012; Chan et al., 2011) are also important topics for research and overlap with 'approach'. Articles regarding the themes 'process' and 'model' concentrate on the development of novel AI applications for innovation, while articles regarding the themes 'business' and 'business-to-business' generally refer to the advancement of existing B2B activities. In addition, information security becomes an important issue, and especially the privacy of customers' information and companies' confidential business information. Accordingly, Sambour and Lu (2015) develop a practical trust-based user-item recommendation intelligent approach which protects companies' and 
consumers' implicit trust information. Nonetheless, the intelligent approaches developed in this period mainly took the sellers' perspective. Thus, research was generally focused on developing innovative AI approaches to support sellers in B2B marketing activities.

\subsection{6-2021: New horizons for AI in B2B marketing}

Studies in this period broadened to include a more holistic view of both information science and business aspects. As shown in Figure 9, the theme 'B2B' becomes the most important research topic again. There is though a new theme, 'customer'. Compared with the preceding period (2011-2015), the primary research focus moves from intelligent approaches to comprehensive activities of B2B marketing innovation from both the seller's and the buyer's perspectives.

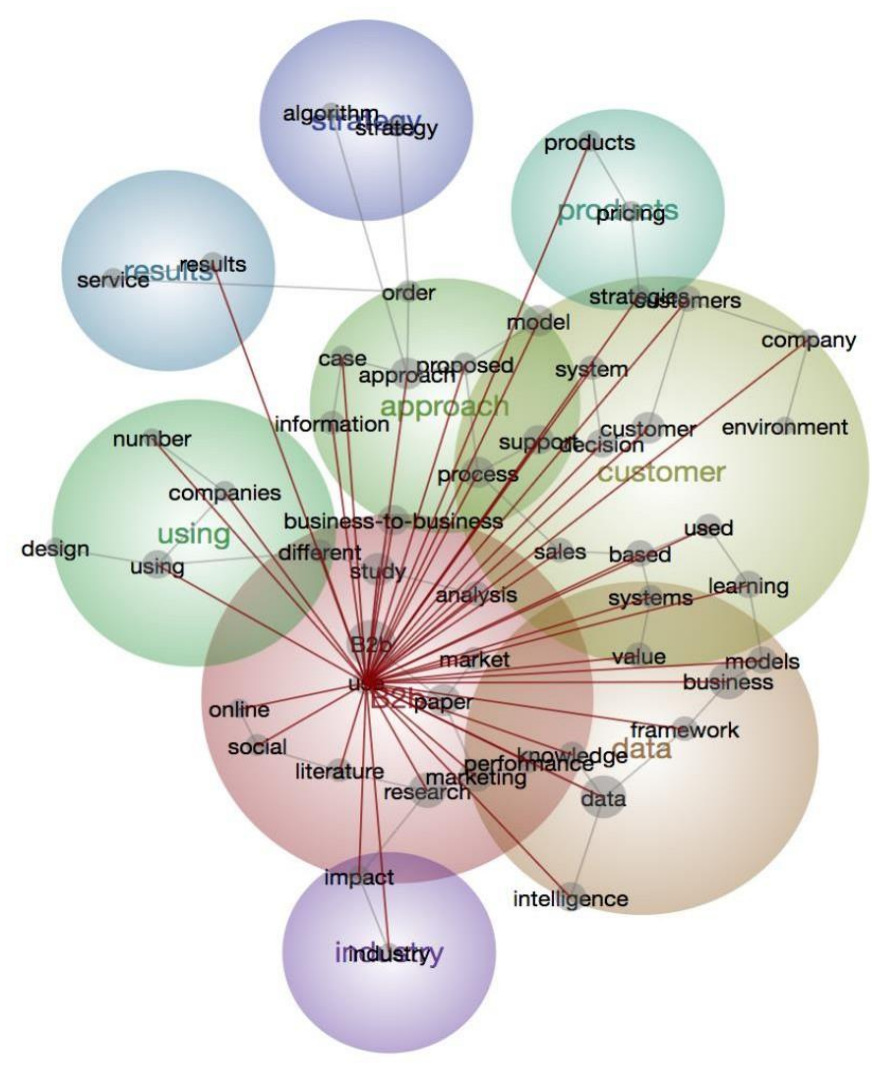

Figure 9: Research themes during the period 2016-2020

Research generally took the seller's perspective in proposing intelligent systems. However, the buyers' (customers') perspective has become more important and gained much research attention. For instance, Rantala et al. (2020) state that it is vital for B2B marketers to consider problems from the customers' perspective and analyse the information of buyers. Therefore, prospective research was conducted to concentrate on 
customer value generation and real-time AI for customer information management (Koponen and Rytsy, 2020; Bahrami et al., 2020). It aims to help B2B marketers to develop appropriate strategies for different customer segments, create real-time information management as well as generate recommendations to customers in their buying decisions. Other important themes are 'data' (Semerádová andWeinlich, 2019; Goul, 2018), 'industry' (Wang et al., 2020a; Sheikh et al., 2019) and 'approach' (Klimanov and Tretyak, 2019; Chang et al., 2019). For example, the theme 'industry' refers to studies conducted in different B2B industries. In short, these themes indicate the maturity of AI as well as the broader implications of $\mathrm{AI}$ as an enabler for innovation in various $\mathrm{B} 2 \mathrm{~B}$ marketing respects.

\subsection{Directions for future research}

To identify the directions for future research, a content analysis was performed based on the 90 articles published from 2016 to 2021 (see Figure 10). The articles published before 2016 were removed from the analysis for two main reasons. On the one hand, most of the 'future' directions suggested before 2016 may already have been addressed. On the other hand, the articles published from 2016 to 2021 suggest a broader perspective compared with the articles published before 2016. Therefore, it is expected that the analysis of these articles can generate more insightful suggestions for future research.

Fig 10: Future themes for research

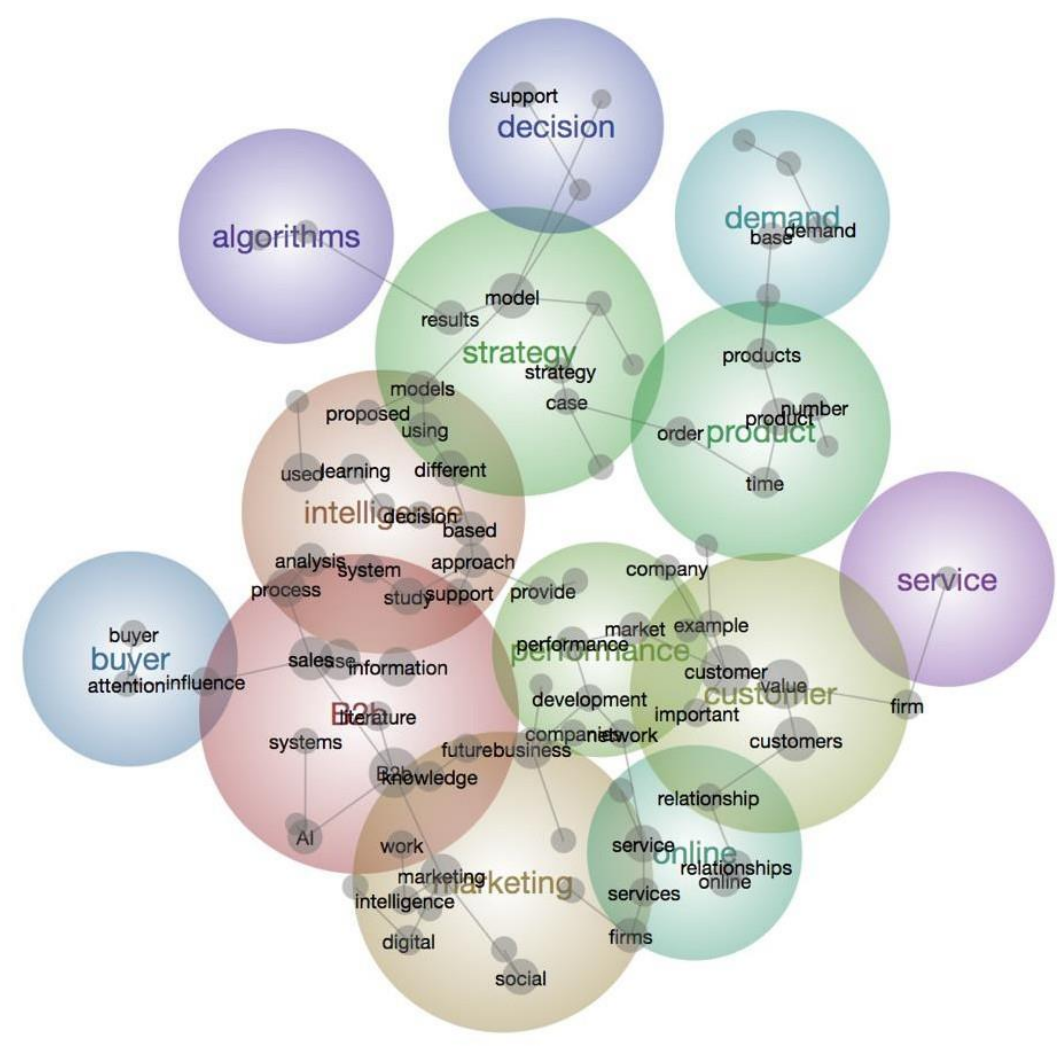


Overall, the themes 'B2B', 'intelligence' and 'marketing' are still the most significant research topics. Also, the overlaps among these themes indicate that more studies are required to integrate these topics. Other themes are less significant, such as 'customer', 'performance', 'online', 'strategy', 'buyer', 'service', 'product', 'demand' and 'decision'. These themes are tightly packed and overlap with each other, indicating future research needs to take a more comprehensive view of the research topic of AI-enabled B2B marketing innovation.

A few promising directions have been determined. First, the analysis suggests that the theme 'strategy' should play a critical part in future studies. The theme of strategy overlaps and connects with other themes, such as 'intelligence', 'decision', 'product' and 'algorithms'. Thus, future research should concentrate on developing more advanced intelligent systems for improving companies' strategic decision-making and product service management. The theme 'customer' is also of particular interest here. CRM is a vital part of B2B marketing, and this suggests that future studies should develop advanced intelligent systems to analyse the information from customers (Meire et al., 2017; Sheikh et al., 2019; Moghaddam et al., 2017). This is consistent with our results - the theme 'customer' reflects an important area for future research. It also overlaps with themes such as 'company performance', 'online', 'product' and 'service'. This indicates that companies' marketing performance and online services will be critical elements for companies in managing their customers effectively in the future.

\section{Conclusion and limitations}

The literature on AI-enabled B2B marketing innovation has increased remarkably, to the extent that examining and summarising the proliferation of research has become a complex issue. Accordingly, this study provides an extensive and holistic review of the literature. By using a bibliometric analysis, this study reviews the literature published from 1990 to 2021 . The results contribute by 1) obtaining and comparing the most influential works based on a series of analyses; 2) identifying five domains of research into how AI can be used for facilitating B2B marketing innovation; and 3) classifying relevant articles into five different time periods in order to identify both past trends and future directions in this specific field.

The analysis suggests many ways for practitioners as well as companies to leverage 
AI technologies to achieve better B2B marketing innovation. The findings can equip B2B marketers with a different perspective on the benefits of using AI for various business activities in their daily operations. For instance, B2B marketers can adopt predictive algorithms and machine learning techniques to create a synthetic profile for both current and potential consumers to improve customer relationship management efforts and explore new customers. Moreover, AI techniques can enable B2B marketers to develop a decision support process for managing and analysing companies' sales data. The new information given by the decision support system can help B2B marketers to gain more new sales opportunities and decrease their sales forecasting errors. Also, B2B marketers should leverage more AI techniques such as machine learning model in their collaboration and negotiation processes to co-create value with their partner companies. During these value co-creation processes, AI techniques can enhance the connection between business partners and improve the quality of negotiation processes. Additionally, managers can transform their companies' operations management model from a traditional model to a digital intelligence model by using AI techniques. For instance, managers can apply AI operation system to their merchandise management, procurement management and workflow management for reaching better operations performance. Last but not the least, managers should choose and learn a framework of using AI in B2B marketing that is most suitable for their companies, and all the related employees (e.g. marketing employees, operations management employees) need to have AI implication training. Improving employees' AI knowledge can not only accelerate the companies' innovation development, but also pave the road for companies to overcome challenges in the future. Thus, through our identified five domains, practitioners can assess their current use of AI ability in terms of their conceptualisation capabilities, technological applications, and identify their future needs in the relevant domains in order to make appropriate decisions on whether to invest in AI. The research outcomes can help companies to better realise their digital marketing innovation strategy through the use of AI.

Nonetheless, there are some limitations to this study. First of all, this study pays a particular attention to the B2B market, and the results are based on studies published through to 2021. In the rapidly changing field of AI and B2B marketing studies, similar studies over the near future may produce different results. Secondly, although bibliometric analysis is an effective method to study trends in a specific field, it has inherent weaknesses due to the specific characteristics of academic research that may overestimate 
one area and underestimate another (Kumar et al., 2020). Last but not least, the content and visualisation analysis in this study was conducted using Leximancer, and the results may be different if other techniques are used. However, despite these specific limitations, the information provided in this research will be of great utility for scholars as well as practitioners interested in $\mathrm{AI}$ and $\mathrm{B} 2 \mathrm{~B}$ marketing innovation.

\section{References}

Ahn, J.Y., Kim, S.K. and Han, K.S., 2003. On the design concepts for CRM system. Industrial Management \& Data Systems.

Ardito, L., Scuotto, V., Del Giudice, M. and Petruzzelli, A.M., 2019. A bibliometric analysis of research on Big Data analytics for business and management. Management Decision, 57(8), pp. 1993-2009

Argoneto, P. and Renna, P., 2010. Production planning, negotiation and coalition integration: A new tool for an innovative e-business model. Robotics and ComputerIntegrated Manufacturing, 26(1), pp.1-12.

Backhaus, K., Becker, J., Beverungen, D., Frohs, M., Müller, O., Weddeling, M., Knackstedt, R. and Steiner, M., 2010. Enabling individualized recommendations and dynamic pricing of value-added services through willingness-to-pay data. Electronic Markets, 20(2), pp.131-146.

Baesens, B., Verstraeten, G., Van den Poel, D., Egmont-Petersen, M., Van Kenhove, P. and Vanthienen, J., 2004. Bayesian network classifiers for identifying the slope of the customer lifecycle of long-life customers. European Journal of Operational Research, 156(2), pp.508-523.

Bahrami, M., Bozkaya, B. and Balcisoy, S., 2020. Using Behavioral Analytics to Predict Customer Invoice Payment. Big Data, 8(1), pp.25-37.

Behzadian, M., Kazemzadeh, R.B., Albadvi, A. and Aghdasi, M., 2010. PROMETHEE: A comprehensive literature review on methodologies and applications. European journal of Operational research, 200(1), pp.198-215.

Belanche, D., Casaló, L.V. and Flavián, C., 2019. Artificial Intelligence in FinTech: understanding robo-advisors adoption among customers. Industrial Management \& Data Systems.

Biehl, M. and Kim, H., 2003. Electronic marketplaces versus enterprise resource planning: a comparison and decision methodology for supply chain management. International Journal of Technology, Policy and Management, 3(3-4), pp.262-284.

Bohanec, M., Borštnar, M.K. and Robnik-Šikonja, M., 2017b. Explaining machine learning models in sales predictions. Expert Systems with Applications, 71, pp.416-428.

Bohanec, M., Robnik-Šikonja, M. and Borštnar, M.K., 2017a. Organizational learning supported by machine learning models coupled with general explanation methods: A Case of B2B sales forecasting. Organizacija, 50(3), pp.217-233. 
Bohanec, M., Robnik-Šikonja, M. and Borštnar, M.K., 2017c. Decision-making framework with double-loop learning through interpretable black-box machine learning models. Industrial Management \& Data Systems, Vol. 117 No. 7, pp. 1389-1406.

Bottani, E., Centobelli, P., Gallo, M., Kaviani, M.A., Jain, V. and Murino, T., 2019. Modelling wholesale distribution operations: an artificial intelligence framework. Industrial Management \& Data Systems.

Brosan, F., 2012. Business intelligence: What works where in B2B digital marketing. Journal of Direct, Data and Digital Marketing Practice, 14(2), pp. 154-159.

Calosso, T., Cantamessa, M. and Gualano, M., 2004. Negotiation support for make-to-order operations in business-to-business electronic commerce. Robotics and ComputerIntegrated Manufacturing, 20(5), pp.405-416.

Castellano, N.G. and Del Gobbo, R., 2018. Strategic mapping: relationships that count. Management Decision.

Chan, F.T.S., Chan, H.K., Ip, R.W.L. and Lau, H.C.W., 2007. A decision support system for supplier selection in the airline industry. Proceedings of the Institution of Mechanical Engineers, Part B: Journal of Engineering Manufacture, 221(4), pp.741-758.

Chan, F.T.S., Shukla, M., Tiwari, M.K., Shankar, R. and Choy, K.L., 2011. B2B multiattribute e-procurement: an artificial immune system based goal programming approach. International Journal of Production Research, 49(2), pp.321-341.

Chan, H.K., 2010. Agent-based factory level wireless local positioning system with ZigBee technology. IEEE Systems Journal, 4(2), pp.179-185.

Chan, H.K., Lacka, E., Yee, R.W. and Lim, M.K., 2017. The role of social media data in operations and production management. International Journal of Production Research, 55(17), pp.5027-5036.

Chan, H.K., Wang, X., Lacka, E. and Zhang, M., 2016. A mixed-method approach to extracting the value of social media data.Production and Operations Management, 25(3), pp.568-583.

Chan, S.L. and Ip, W.H., 2011. A dynamic decision support system to predict the value of customer for new product development. Decision Support Systems, 52(1), pp.178188.

Chang, C.T., Zhao, W.X. and Hajiyev, J., 2019. An Integrated Smartphone and Tariff Plan Selection for Taxi Service Operators: MCDM and RStudio Approach. IEEE Access, 7, pp.31457-31472.

Chang, T.H., Lee, J.Y. and Chen, R.H., 2008. The effects of customer value on loyalty and profits in a dynamic competitive market. Computational Economics, 32(3), p.317.

Chiu, D.K., Cheung, S.C., Hung, P.C., Chiu, S.Y. and Chung, A.K., 2005. Developing eNegotiation support with a meta-modeling approach in a web services environment. Decision support systems, 40(1), pp.51-69.

Choi, J.H. and Kim, J.W., 2008. A hybrid decision support model for selecting highly qualified suppliers. Journal of Computer Information Systems, 49(1), pp.90-100.

Choi, T.M., Chan, H.K. and Yue, X., 2016. Recent development in big data analytics for business operations and risk management. IEEE transactions on cybernetics, 47(1), pp.81-92. 
Choy, K.L., Fan, K.K. and Lo, V., 2003. Development of an intelligent customer-supplier relationship management system: the application of case-based reasoning. Industrial Management \& Data Systems.

Chun, A.H.W. and Wong, R.Y., 2007. Improving quality of crane-lorry assignments with constraint programming. IEEE Transactions on Systems, Man, and Cybernetics, Part C (Applications and Reviews), 37(2), pp.268-277.

Crain, R.L. and Mahard, R.E., 1983. The effect of research methodology on desegregationachievement studies: A meta-analysis. American Journal of Sociology, 88(5), pp.839- 854 .

Dadouchi, C. and Agard, B., 2018. Lowering penalties related to stock-outs by shifting demand in product recommendation systems. Decision Support Systems, 114, pp.6169.

Daskou, S. and Mangina, E.E., 2003. Artificial intelligence in managing market relationships: the use of intelligence agents. Journal of Relationship Marketing, 2(12), pp.85-102.

Davenport, T., Guha, A., Grewal, D. and Bressgott, T., 2020. How artificial intelligence will change the future of marketing. Journal of the Academy of Marketing Science, 48(1), pp.24-42.

De Heer, A.J., Design of a DSS for Business-to-Business Networking in Emerging Industries.

Demirkan, H., Sen, S., Goul, M. and Nichols, J., 2012. Ensuring reliability in B2B services: Fault tolerant inter-organizational workflows. Information Systems Frontiers, 14(3), pp.765-788.

Dikow, H., Hasan, O., Kosch, H., Brunie, L. and Sornin, R., 2015. Improving the accuracy of Business-to-Business (B2B) reputation systems through rater expertise prediction. Computing, 97(1), pp.29-49.

Dong, Y., Huang, X., Sinha, K.K. and Xu, K., 2014. Collaborative demand forecasting: toward the design of an exception-based forecasting mechanism. Journal of Management Information Systems, 31(2), pp.245-284.

Duan, Y., Edwards, J.S. and Dwivedi, Y.K., 2019. Artificial intelligence for decision making in the era of Big Data-evolution, challenges and research agenda. International Journal of Information Management, 48, pp.63-71.

Dwivedi, Y. K., Hughes, L., Ismagilova, E., Aarts, G., Coombs, C., Crick, T., ... \& Galanos, V., 2019b. Artificial Intelligence (AI): Multidisciplinary perspectives on emerging challenges, opportunities, and agenda for research, practice and policy. International Journal of Information Management, 101994.

DoI:https://doi.org/10.1016/j.ijinfomgt.2019.08.002

Dwivedi, Y. K., Ismagilova, E., Rana, N. P., \& Weerakkody, V. 2019a. Use of social media by b2b companies: systematic literature review and suggestions for future research. In Conference on e-Business, e-Services and e-Society (pp. 345-355). Springer, Cham.

Dwivedi, Y.K., Ismagilova, E., Hughes, D.L., Carlson, J., Filieri, R., Jacobson, J., Jain, V., Karjaluoto, H., Kefi, H., Krishen, A.S, Kumar, V., 2020. Setting the future of digital and social media marketing research: Perspectives and research propositions. 
International Journal of Information Management, p.102168. DoI: https://doi.org/10.1016/j.ijinfomgt.2020.102168

Evans, D. and Kowanko, I., 2000. Literature reviews: evolution of a research methodology. The Australian journal of advanced nursing: a quarterly publication of the Royal Australian Nursing Federation, 18(2), pp.33-38.

Fensel, D., Ding, Y., Omelayenko, B., Schulten, E., Botquin, G., Brown, M. and Flett, A., 2001. Product data integration in B2B e-commerce. IEEE Intelligent Systems, 16(4), pp.54- 59.

Fernandez, L.M.V., Nicolas, C. and Merigó, J.M., 2019. Industrial marketing research: a bibliometric analysis (1990-2015). Journal of Business \& Industrial Marketing, 34 (3), pp. 550-560.

Fillmore, P.R., Fillmore Peter R, 2010. Method for Sales Forecasting in Business-toBusiness Sales Management. U.S. Patent Application 12/711,097.

Fish, K.E., Barnes, J.H. and AikenAssistant, M.W., 1995. Artificial neural networks: a new methodology for industrial market segmentation. Industrial Marketing Management, 24(5), pp.431-438.

Fu, X., Zeng, X.J., Luo, X.R., Wang, D., Xu, D. and Fan, Q.L., 2017. Designing an intelligent decision support system for effective negotiation pricing: A systematic and learning approach. Decision Support Systems, 96, pp.49-66.

Gentner, D., Stelzer, B., Ramosaj, B. and Brecht, L., 2018. Strategic Foresight of Future B2B Customer Opportunities through Machine Learning. Technology Innovation Management Review, 8(10), pp. 5-17.

Gessner, G. and Scott Jr, R.A., 2009. Using business intelligence tools to help manage costs and effectiveness of business-to-business inside-sales programs. Information Systems Management, 26(2), pp.199-208.

Giri, C., Jain, S., Zeng, X. and Bruniaux, P., 2019. A Detailed Review of Artificial Intelligence Applied in the Fashion and Apparel Industry. IEEE Access, 7, pp.95364-95384.

Goul, M., 2018. APC Forum: Poised Between'a Wild West of Predictive Analytics' and'an Analytics of Things Westworld Frontier'. MIS Quarterly Executive, 17(4).

Grover, P., Kar, A.K. and Dwivedi, Y.K., 2020. Understanding artificial intelligence adoption in operations management: insights from the review of academic literature and social media discussions. Annals of Operations Research, pp.1-37. DoI: https://doi.org/10.1007/s10479-020-03683-9

Hamichi, S., Mangalagiu, D. and Guessoum, Z., 2013. A Multi-Agent System for production networks simulation: Toward a pheromone-based model for agents' coordination. In Supply Chain Management: Concepts, Methodologies, Tools, and Applications (pp. 1666-1682). IGI Global.

Hausman, A., Noori, B. and Salimi, M.H., 2005. A decision- support system for businessto- business marketing. Journal of Business \& Industrial Marketing, 20 (4/5), pp. 226-236. 
Hosseini, S.M.S., Maleki, A. and Gholamian, M.R., 2010. Cluster analysis using data mining approach to develop CRM methodology to assess the customer loyalty. Expert Systems with Applications, 37(7), pp.5259-5264.

Joh, Y.H. and Lee, J.K., 2003. Buyer's customized directory management over sellers'ecatalogs: logic programming approach. Decision Support Systems, 34(2), pp.197212.

Jooste, J.L. and Vlok, P.J., 2015. A decision support model to determine the critical success factors of asset management services. South African Journal of Industrial Engineering, 26(1), pp.27-43.

Kerkkanen, A., Huiskonen, J., Korpela, J. and Pirttila, T., 2012. How do managers perceive the needs of sales forecasting process improvement in a B2B environment. International Journal of Management Practice, 5(2), pp.107-124.

Klimanov, D. and Tretyak, O., 2019. Linking business model research and marketing: new network-based approach to business model analysis. Journal of Business \& Industrial Marketing, 34 (1), pp. 117-136.

Koponen, J.P. and Rytsy, S., 2020. Social presence and e-commerce B2B chat functions. European Journal of Marketing, 54 (6), pp. 1205-1224.

Kot, M.T. and Leszczyński, G., 2020. The concept of intelligent agent in business interactions: is virtual assistant an actor or a boundary object? Journal of Business \& Industrial Marketing, 35 (7), 1155-1164.

Kuechler Jr, W., Vaishnavi, V.K. and Kuechler, D., 2001. Supporting optimization of business- to-business e-commerce relationships. Decision Support Systems, 31(3), pp.363-377.

Kumar, B., Sharma, A., Vatavwala, S. and Kumar, P., 2020. Digital mediation in businessto- business marketing: A bibliometric analysis. Industrial Marketing Management, 85, pp.126-140.

Kumar, R.R.V., Kumar, M.A. and Soman, K.P., 2016. Cuisine prediction based on ingredients using tree boosting algorithms. Indian Journal of Science and Technology, 9(45), p.12.

Lacka, E., Chan, H.K. and Wang, X., 2020. Technological advancements and B2B international trade: A bibliometric analysis and review of industrial marketing research. Industrial Marketing Management, 88, pp.1-11. DoI:https://doi.org/10.1016/j.indmarman.2020.04.007

Laínez, J.M., Reklaitis, G.V. and Puigjaner, L., 2010. Linking marketing and supply chain models for improved business strategic decision support. Computers \& Chemical Engineering, 34(12), pp.2107-2117.

Lee, K.C. and Kwon, S., 2008. CAKES-NEGO: Causal knowledge-based expert system for B2B negotiation. Expert Systems with Applications, 35(1-2), pp.459-471.

Lee, Y., Filliben, J.J., Micheals, R.J. and Phillips, P.J., 2013. Sensitivity analysis for biometric systems: A methodology based on orthogonal experiment designs. Computer Vision and Image Understanding, 117(5), pp.532-550. 
Lei, T., Xiaoyong, H. and Mingshu, L., 2008. An approach to dynamic service composition based on context negotiation. Journal of Computer Research and Development, 45(11), p.1902.

Leskelä, R.L., Teich, J., Wallenius, H. and Wallenius, J., 2007. Decision support for multiunit combinatorial bundle auctions. Decision Support Systems, 43(2), pp.420-434.

Leung, K.H., Luk, C.C., Choy, K.L., Lam, H.Y. and Lee, C.K., 2019. A B2B flexible pricing decision support system for managing the request for quotation process under ecommerce business environment. International Journal of Production Research, 57(20), pp.6528-6551.

Leung, X.Y., Sun, J. and Bai, B., 2017. Bibliometrics of social media research: A co-citation and co-word analysis. International Journal of Hospitality Management, 66, pp.3545.

Li, S. and Li, J.Z., 2009. Hybridising human judgment, AHP, simulation and a fuzzy expert system for strategy formulation under uncertainty. Expert Systems with Applications, 36(3), pp.5557-5564.

Li, S., 2000. The development of a hybrid intelligent system for developing marketing strategy. Decision Support Systems, 27(4), pp.395-409.

Li, S., 2007. AgentStra: an Internet-based multi-agent intelligent system for strategic decision- making. Expert Systems with Applications, 33(3), pp.565-571.

Li, X., Wu, C. and Liu, L.C., 2003. Research on vendor selection in vertical business-tobusiness marketplace. Jisuanji Jicheng Zhizao Xitong/Computer Integrated Manufacturing System(China), 9(4), pp.270-275.

Liang, T.P. and Liu, Y.H., 2018. Research landscape of business intelligence and big data analytics: A bibliometrics study. Expert Systems with Applications, 111, pp.2-10.

Lin, K.P., Yu, C.M. and Chen, K.S., 2019. Production data analysis system using novel process capability indices-based circular economy. Industrial Management \& Data Systems.

Lin, P.C., Wang, J. and Chin, S.S., 2009. Dynamic optimisation of price, warranty length and production rate. International Journal of Systems Science, 40(4), pp.411-420.

Lv, Y. and Lin, D., 2017. Design an intelligent real-time operation planning system in distributed manufacturing network. Industrial Management \& Data Systems.

Maggin, D.M., O'Keeffe, B.V. and Johnson, A.H., 2011. A quantitative synthesis of methodology in the meta-analysis of single-subject research for students with disabilities: 1985-2009. Exceptionality, 19(2), pp.109-135.

Martínez-López, F.J. and Casillas, J., 2013. Artificial intelligence-based systems applied in industrial marketing: An historical overview, current and future insights. Industrial Marketing Management, 42(4), pp.489-495.

Meire, M., Ballings, M. and Van den Poel, D., 2017. The added value of social media data in B2B customer acquisition systems: A real-life experiment. Decision Support Systems, 104, pp.26-37.

Mentzer, J.T. and Gandhi, N., 1993. Expert systems in industrial marketing. Industrial marketing management, 22(2), pp.109-116. 
Michel, R., 2000. Business intelligence solutions from reports, to data warehouse tools, to analytic apps for e-business. Manufacturing Systems, 18(12), pp. 80, 82.

Mishra, D., Gunasekaran, A., Papadopoulos, T. and Childe, S.J., 2018. Big Data and supply chain management: a review and bibliometric analysis. Annals of Operations Research, 270(1-2), pp.313-336.

Moghaddam, S.Q., Abdolvand, N. and Harandi, S.R., 2017. A RFMV Model and Customer Segmentation Based on Variety of Products. Information Systems \& Telecommunication, p.155.

Moliner-Velazquez, B., Fuentes-Blasco, M. and Gil-Saura, I., 2014. Value antecedents in relationship between tourism companies. Journal of Business \& Industrial Marketing.

Morioka, S.N. and de Carvalho, M.M., 2016. A systematic literature review towards a conceptual framework for integrating sustainability performance into business. Journal of Cleaner Production, 136, pp.134-146.

Noori, B., 2013. A case-based reasoning system for adapting selling. International Journal of Electronic Customer Relationship Management, 7(3-4), pp.219-230.

Ozturk, O.C. and Karabat1, S., 2017. A decision support framework for evaluating revenue performance in sequential purchase contexts. European Journal of Operational Research, 263(3), pp.922-934.

Pandey, N., Nayal, P. and Rathore, A.S., 2020. Digital marketing for B2B organizations: structured literature review and future research directions. Journal of Business \& Industrial Marketing. DoI: https://doi.org/10.1108/JBIM-06-2019-0283

Park, J.H. and Park, S.C., 2003. Agent-based merchandise management in business-tobusiness electronic commerce. Decision Support Systems, 35(3), pp.311-333.

Paschen, J., Kietzmann, J. and Kietzmann, T.C., 2019. Artificial intelligence (AI) and its implications for market knowledge in B2B marketing. Journal of Business \& Industrial Marketing, 34(7), pp. 1410-1419.

Paschen, J., Paschen, U., Pala, E. and Kietzmann, J., 2020b. Artificial intelligence (AI) and value co-creation in B2B sales: Activities, actors and resources. https://www.divaportal.org/smash/get/diva2: 1400549/FULLTEXT01.pdf

Paschen, J., Wilson, M. and Ferreira, J.J., 2020a. Collaborative intelligence: How human and artificial intelligence create value along the B2B sales funnel. Business Horizons. DoI: https://doi.org/10.1016/j.bushor.2020.01.003

Pathak, B.K. and Zeng, A.Z., 2001. Achieving Information Integration in Supply Chain Management Through E-Hubs: Concepts and Analysis.

Paulraj, D., Swamynathan, S. and Madhaiyan, M., 2012. Process model-based atomic service discovery and composition of composite semantic web services using web ontology language for services (OWL-S). Enterprise Information Systems, 6(4), pp.445-471.

Piao, C.H., Zhao, J. and Zheng, L.J., 2009. Research on entropy-based collaborative filtering algorithm and personalized recommendation in e-commerce. Service Oriented Computing and Applications, 3(2), pp.147-157. 
Pillai, R., Sivathanu, B. and Dwivedi, Y.K., 2020. Shopping intention at AI-powered automated retail stores (AIPARS). Journal of Retailing and Consumer Services, 57, p.102207.

Prior, D.D. and Keränen, J., 2020. Revisiting contemporary issues in B2B marketing: It's not just about artificial intelligence. Australasian Marketing Journal (AMJ), 28(2), pp.83- 89.

Ramos-Rodriguez, A. R., \& Ruiz-Navarro, J. (2004). Changes in the intellectual structure of strategic management research: A bibliometric study of the Strategic Management Journal, 1980-2000. Strategic Management Journal, 25(10), 9811004.

Rantala, T., Apilo, T., Palomäki, K. and Valkokari, K., 2020. Selling Data-Based Value in Business-to-Business Markets. Technology Innovation Management Review, 10(1), pp. 45-53.

Renna, P., 2009. A multi-agent system architecture for business-to-business applications.

Rich, M. and Latusek, W.P., 2010. B2B relationship marketing analytical support with GBC modeling. Journal of Business \& industrial marketing, 25(3), pp. 209-219

Riley, R.A. and Kleist, V.F., 2005. The biometric technologies business case: a systematic approach. Information Management \& Computer Security, 13(2), pp. 89-105.

Schaeffer, S.E. and Sanchez, S.V.R., 2020. Forecasting client retention-A machinelearning approach. Journal of Retailing and Consumer Services, 52, p.101918.

Schellhorn, H., 2009. A double-sided multiunit combinatorial auction for substitutes: Theory and algorithms. European Journal of Operational Research, 197(2), pp.799808.

Semerádová, T. and Weinlich, P., 2019. Computer estimation of customer similarity with Facebook lookalikes: Advantages and disadvantages of hyper-targeting. IEEE Access, 7, pp.153365-153377.

Sen, A.K., Bagchi, A. and Chakraborty, S., 2020. Designing information feedback for bidders in multi-item multi-unit combinatorial auctions. Decision Support Systems, 130, p.113230.

Shambour, Q. and Lu, J., 2015. An effective recommender system by unifying user and item trust information for B2B applications. Journal of Computer and System Sciences, 81(7), pp.1110-1126.

Sheikh, A., Ghanbarpour, T. and Gholamiangonabadi, D., 2019. A preliminary study of fintech industry: A two-stage clustering analysis for customer segmentation in the B2B setting. Journal of Business-to-Business Marketing, 26(2), pp.197-207.

Silverman, B.G., Bachann, M. and Al-Akharas, K., 2001. Implications of buyer decision theory for design of e-commerce websites. International Journal of HumanComputer Studies, 55(5), pp.815-844.

Simonite, T., 2018. Google's AI software is learning to make AI software. [online] MIT Technology Review. 
Sohrabpour, V., Oghazi, P., Toorajipour, R. and Nazarpour, A., 2021. Export sales forecasting using artificial intelligence. Technological Forecasting and Social Change, 163, p.120480.

Søilen, K.S., 2016. Users' perceptions of Data as a Service (DaaS). Journal of Intelligence Studies in Business, 6(2), pp. 43-51.

Steinberg, M. and Plank, R.E., 1990. Implementing expert systems into business- tobusiness marketing practice. Journal of Business \& Industrial Marketing, 5 (2), pp. $15-26$.

Steinhoff, L., Arli, D., Weaven, S. and Kozlenkova, I.V., 2019. Online relationship marketing. Journal of the Academy of Marketing Science, 47(3), pp.369-393.

Sun, X., Tang, W., Ye, T., Zhang, Y., Wen, B. and Zhang, L., 2014. Integrated care: a comprehensive bibliometric analysis and literature review. International journal of integrated care, 14.

Talluri, S., Narasimhan, R. and Viswanathan, S., 2007. Information technologies for procurement decisions: a decision support system for multi-attribute e-reverse auctions. International Journal of Production Research, 45(11), pp.2615-2628.

Tan, P.S., Lee, S.S.G. and Goh, A.E.S., 2012. Multi-criteria decision techniques for contextaware B2B collaboration in supply chains. Decision Support Systems, 52(4), pp.779789.

Teich, J., Wallenius, H. and Wallenius, J., 1999. Multiple-issue auction and market algorithms for the world wide web. Decision support systems, 26(1), pp.49-66.

Teich, J.E., Wallenius, H., Wallenius, J. and Koppius, O.R., 2004. Emerging multiple issue e- auctions. European Journal of Operational Research, 159(1), pp.1-16.

Tsafarakis, S., Saridakis, C., Baltas, G. and Matsatsinis, N., 2013. Hybrid particle swarm optimization with mutation for optimizing industrial product lines: An application to a mixed solution space considering both discrete and continuous design variables. Industrial Marketing Management, 42(4), pp.496-506.

University Wrold News, 2018. Too much academic research is being published, available at: https://www.universityworldnews.com/post.php?story=20180905095203579

Van Der Aalst, W.M., Reijers, H.A., Weijters, A.J., van Dongen, B.F., De Medeiros, A.A., Song, M. and Verbeek, H.M.W., 2007. Business process mining: An industrial application. Information Systems, 32(5), pp.713-732.

van Loon, P. and Van Wassenhove, L.N., 2018. Assessing the economic and environmental impact of remanufacturing: a decision support tool for OEM suppliers. International Journal of Production Research, 56(4), pp.1662-1674.

Vincent, O.R., Makinde, A.S. and Akinwale, A.T., 2017. A cognitive buying decisionmaking process in B2B e-commerce using Analytic-MLP. Electronic Commerce Research and Applications, 25, pp.59-69.

Wamba, S.F., Bawack, R.E., Guthrie, C., Queiroz, M.M. and Carillo, K.D.A., 2020. Are we preparing for a good AI society? A bibliometric review and research agenda. Technological Forecasting and Social Change, p.120482. 
Wang, Y., Rod, M., Deng, Q. and Ji, S., 2020a. Exploiting business networks in the age of social media: the use and integration of social media analytics in B2B marketing. Journal of Business \& Industrial Marketing. DoI: https://doi.org/10.1108/JBIM-052019-0173.

Wang, Y., Rod, M., Ji, S. and Deng, Q., 2017. Social media capability in B2B marketing: toward a definition and a research model. Journal of Business \& Industrial Marketing. 32(8), pp. 1125-1135.

Wang, Y., Zhang, M., Tse, Y. K., \& Chan, H. K. 2020b. Unpacking the impact of social media analytics on customer satisfaction: Do external stakeholder characteristics matter?. International Journal of Operations and Production Management. 40(5), 647-669

Wierenga, B. and Ophuis, P.A.O., 1997. Marketing decision support systems: Adoption, use, and satisfaction. International Journal of Research in Marketing, 14(3), pp.275290.

Wilson, R.D. and Bettis-Outland, H., 2019. Can artificial neural network models be used to improve the analysis of B2B marketing research data? Journal of Business \& Industrial Marketing, 35(3), pp. 495-507.

Wu, D., Zhang, G. and Lu, J., 2014. A fuzzy preference tree-based recommender system for personalized business-to-business e-services. IEEE Transactions on Fuzzy Systems, 23(1), pp.29-43.

Xia, M., Stallaert, J. and Whinston, A.B., 2005. Solving the combinatorial double auction problem. European Journal of Operational Research, 164(1), pp.239-251.

Xu, D. and Wang, H., 2002. Multi-agent collaboration for B2B workflow monitoring. Knowledge-Based Systems, 15(8), pp.485-491.

Xu, S.X. and Huang, G.Q., 2017. Efficient Multi- Attribute Multi- Unit Auctions for B2B E- Commerce Logistics. Production and Operations Management, 26(2), pp.292304.

Xu, X., Chen, X., Jia, F., Brown, S., Gong, Y. and Xu, Y., 2018. Supply chain finance: A systematic literature review and bibliometric analysis. International Journal of Production Economics, 204, pp.160-173.

Yagüe, M., Rodríguez, E. and Delgado, J., 2007. Verification algorithms for governed use of multimedia content. Online Information Review, 31 (1), pp. 38-58.

Yang, Z., Shang, C., Liu, Q. and Zhao, C., 2010. A dynamic web services composition algorithm based on the combination of ant colony algorithm and genetic algorithm. Journal of Computational Information Systems, 6(8), pp.2617-2622.

Yin, J., Cao, B., Deng, S. and Wu, Z., 2012. Process Discovery from the Log of Business Rule Engine. International Journal of Innovative Computing Information and Control, 8(7 B), pp.5277-5293.

Zahay, D. and Griffin, A., 2004. Customer learning processes, strategy selection, and performance in business- to- business service firms. Decision Sciences, 35(2), pp.169-203. 